\title{
Development of Models to Simulate Tracer Behavior in Enhanced Geothermal Systems
}

\section{Status Report}

\author{
MD Williams ${ }^{1}$ \\ D Newell ${ }^{2}$ \\ VR Vermeul $^{1}$ \\ T Watson ${ }^{3}$ \\ PW Reimus ${ }^{2}$ \\ ${ }^{1}$ Pacific Northwest National Laboratory \\ 2 Los Alamos National Laboratory \\ ${ }^{3}$ Brookhaven National Laboratory
}

June 2010

\section{Pacific Northwest}

NATIONAL LABORATORY

Proudly Operated by Battelle Since 1965 


\title{
DISCLAIMER
}

This report was prepared as an account of work sponsored by an agency of the United States Government. Neither the United States Government nor any agency thereof, nor Battelle Memorial Institute, nor any of their employees, makes any warranty, express or implied, or assumes any legal liability or responsibility for the accuracy, completeness, or usefulness of any information, apparatus, product, or process disclosed, or represents that its use would not infringe privately owned rights. Reference herein to any specific commercial product, process, or service by trade name, trademark, manufacturer, or otherwise does not necessarily constitute or imply its endorsement, recommendation, or favoring by the United States Government or any agency thereof, or Battelle Memorial Institute. The views and opinions of authors expressed herein do not necessarily state or reflect those of the United States Government or any agency thereof.

\author{
PACIFIC NORTHWEST NATIONAL LABORATORY \\ operated by \\ BATTELLE \\ for the \\ UNITED STATES DEPARTMENT OF ENERGY \\ under Contract DE-AC05-76RL01830
}

Printed in the United States of America

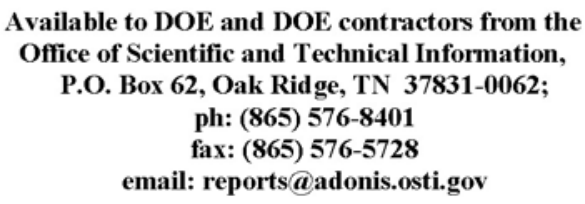

\footnotetext{
Available to the public from the National Technical Information Service, U.S. Department of Commerce, 5285 Port Royal Rd., Springfield, VA 22161 ph: (800) 553-6847 fax: $(703) 605-6900$ email: orders $@$ ntis.fedworld.gov online ordering: http://www.ntis.gov/ordering.htm
} 


\title{
Development of Models to Simulate Tracer Behavior in Enhanced Geothermal Systems
}

\section{STATUS REPORT}

\author{
MD Williams $^{1} \quad$ D Newell $^{2}$ \\ VR Vermeul $^{1} \quad$ T Watson $^{3}$ \\ PW Reimus ${ }^{2}$ \\ ${ }^{1}$ Pacific Northwest National Laboratory \\ ${ }^{2}$ Los Alamos National Laboratory \\ ${ }^{3}$ Brookhaven National Laboratory
}

June 2010

Prepared for

the U.S. Department of Energy

under Contract DE-AC05-76RL01830

Pacific Northwest National Laboratory

Richland, Washington 99352 



\section{Summary}

A recent report found that power and heat produced from engineered (or enhanced) geothermal systems (EGSs) could have a major impact on the United States while minimally impacting the environment. EGS resources differ from high-grade hydrothermal resources in that they lack sufficient temperature distribution, permeability/porosity, fluid saturation, or recharge of reservoir fluids. Therefore, quantitative characterization of temperature distributions and the surface area available for heat transfer in EGS is necessary for the design and commercial development of geothermal energy of a potential EGS site. The goal of this project is to provide integrated tracer and tracer interpretation tools to facilitate this characterization. Subsurface modeling capabilities are an important component of this project for both the design of suitable tracers and the interpretation of data from in situ tracer tests, be they single- or multi-well tests. The purpose of this report is to describe the simulation plan and the status of model development for simulating tracer tests for characterizing EGS parameters. 



\section{Acronyms and Abbreviations}

$\begin{array}{ll}\text { BNL } & \text { Brookhaven National Laboratory } \\ \text { CEC } & \text { cation exchange capacity } \\ \text { EGS } & \text { engineered (or enhanced) geothermal system } \\ \text { LANL } & \text { Los Alamos National Laboratory } \\ \text { MINC } & \text { multiple interacting continua } \\ \text { NAPL } & \text { non-aqueous phase liquid } \\ \text { PFT } & \text { perfluorinated tracer compound } \\ \text { PNNL } & \text { Pacific Northwest National Laboratory } \\ \text { SA/V } & \text { surface area-to-volume (ratio) } \\ \text { STOMP } & \text { Subsurface Transport Over Multiple Phases }\end{array}$





\section{Contents}

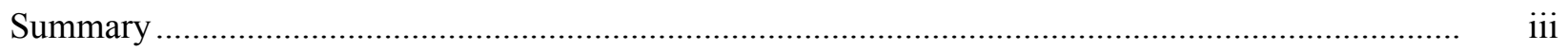

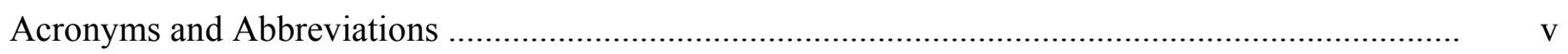

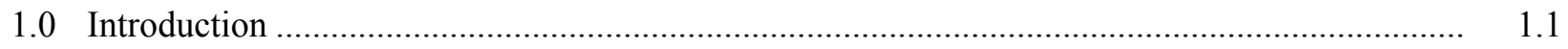

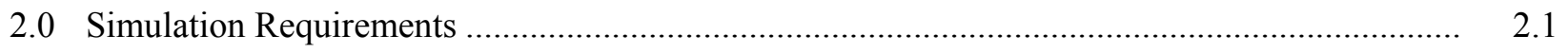

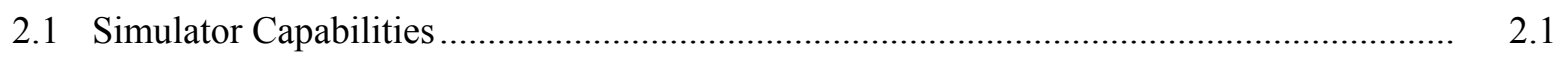

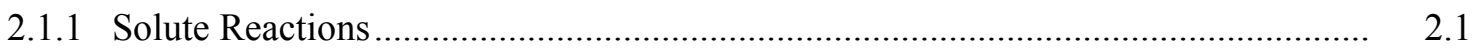

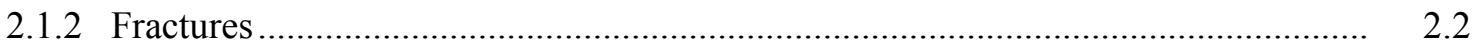

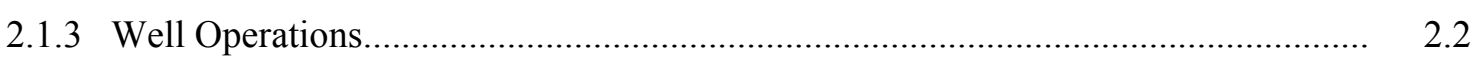

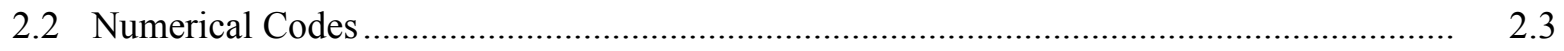

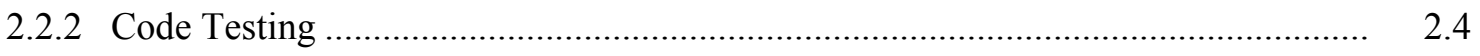

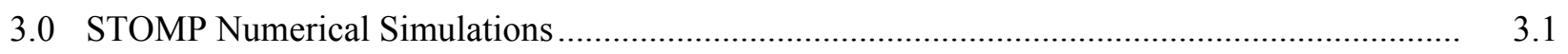

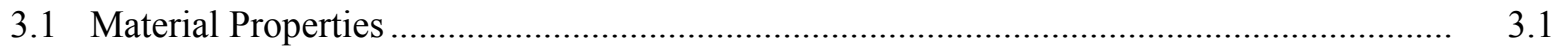

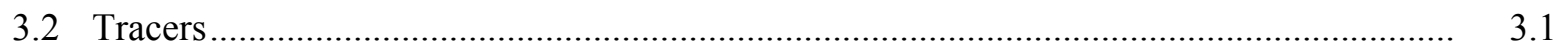

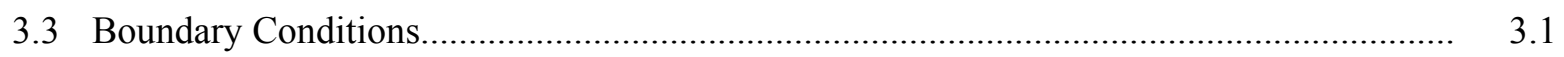

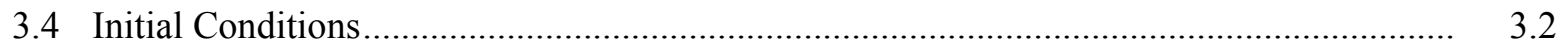

3.5 Operational/Transient Conditions …..................................................................... 3.2

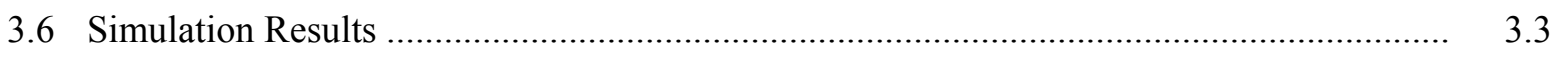

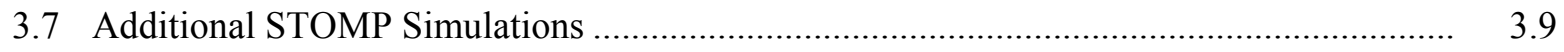

4.0 Semi-Analytical Model Simulations................................................................................ 4.1

4.1 Thermally Degrading Tracers to Predict Thermal Breakthrough..................................... 4.1

4.2 Diffusing Tracers to Estimate SA/V Ratios .............................................................. 4.6

5.0 Multicomponent Numerical Model Simulations of the Use of Cation-Exchanging Tracers for Surface Area Estimation ......................................................................................... 5.1

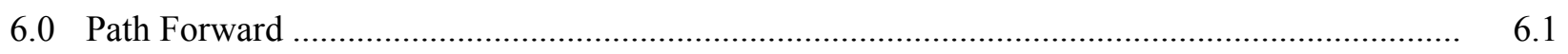

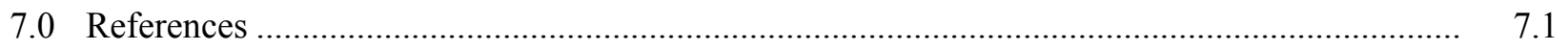




\section{Figures}

3.1. Two-Dimensional, Radially Symmetric, Finite Difference STOMP Grid

3.2. Zoomed View of the Two-Dimensional, Radially Symmetric, Finite Difference STOMP Grid.

3.3. Simulated Temperatures for an Example Single-Well Injection/Shut-in/Withdrawal Test.

3.4. Simulated Conservative Tracer for an Example Single-Well Injection/Shut-in/Withdrawal Test

3.5. Simulated Tracer with Constant Half-Life for an Example Single-Well Injection/Shutin/Withdrawal Test

3.6. Simulated Tracer with Temperature-Dependent Degradation for an Example Single-Well Injection/Shut-in/Withdrawal Test.

3.7. Plot of Simulated Well Concentrations and Injection/Withdrawal Rates for a Single-Well Injection/Withdrawal Test

3.8. Simulated Tracers and Temperatures for an Injection/Shut-in/Withdrawal Test

3.9. Simulated Tracers and Temperatures for an Injection/Shut-in/Withdrawal Test

4.1. Simulated Temperature as a Function of Time and Fractional Distance Between the Injection Well and Production Well (see text for model parameters)

4.2. Simulated Breakthrough Curves of a Conservative Tracer and a Thermally Degrading (Thermally Decaying) Tracer at Three Different Times After the Start of Reservoir Operations

4.3. Ranges of Arrhenius Decay Parameters $A$ and $E_{a}$ (expressed as $\log (A \tau)$ and $E_{a} / \mathrm{RT}$ ) Providing Quantifiable Interpretations of Thermally Degrading Tracers Relative to Conservative Tracers

4.4. Simulated Differences Between Bromide and a Naphthalene Sulfonate Tracer as a Function of SA/V in an EG System Reservoir

5.1. Simulated Differences in Conservative and Cation-Exchanging Tracer Breakthrough Curves for SA/V Values of $10 \mathrm{~cm}^{-1}$ and $20 \mathrm{~cm}^{-1}$

5.2. Simulated Differences in $\mathrm{Rb}^{+}$Breakthrough Curves (brown and red) as a Function of SA/V and CEC in a Single-Well Tracer Test (see text for test assumptions)

\section{Tables}

3.1. Material Properties Used in the Example Simulation 


\subsection{Introduction}

A recent report (MIT 2006) found that electrical power derived from engineered (or enhanced) geothermal systems (EGSs) "represents a large, indigenous resource that could provide base-load electric power and heat that can have a major impact on the United States, while incurring minimal environmental impacts." EGS resources differ from high-grade hydrothermal resources in that they lack sufficient temperature distribution, permeability/porosity, fluid saturation, or recharge of reservoir fluids (MIT 2006). Therefore, quantitative characterization of temperature distributions and the surface area available for heat transfer is necessary for the design and commercial development of a potential EGS site. The goal of this project is to provide integrated tracer-selection and tracer-interpretation tools to facilitate this characterization. To achieve this goal, this project will develop and implement:

- suites of tracers consisting of compounds with different chemical and physical properties that can be injected into wells and will interact in different and measurable ways with the fractured rock matrix (which is the focus of enhanced permeability/porosity for EGS technologies)

- single- and multi-well test designs and corresponding interpretation methods to extract the temperature-distribution and surface-area information from differences in the tracer concentration versus time histories (i.e., breakthrough curves).

The target tracer suite(s) will include 1) compounds that thermally degrade over a defined range of temperatures, 2) partitioning/adsorbing tracers that have a variety of interaction characteristics with rock surfaces, and 3) conservative tracers that provide the basis for differential interpretation. From this tracer information, this project will develop 1) tracers that can be reliably applied to provide quantitative information on temperature distribution and fracture surface area, 2) tracer test designs (both single-well and multi-well) to exploit the use of these tracers, and 3) interpretive methods whereby this information will provide practical guidance to improve heat extraction.

The use of thermally degrading and adsorbing tracers in geothermal applications was first suggested in model simulations conducted by Los Alamos National Laboratory (LANL) during the Fenton Hill Hot Dry Rock geothermal project (Robinson et al. 1988, Nicol and Robinson 1990, Chemburkar et al. 1991). LANL has subsequently used adsorbing tracers and conservative tracers with different diffusion coefficients to estimate surface area-to-volume $(\mathrm{SA} / \mathrm{V})$ ratios in fractured rock groundwater systems (Reimus and Callahan 2007). Differential tracer transport has also been used by Brookhaven National Laboratory (BNL) and others in oil field characterization and in characterization of groundwater and contaminated soil systems (Sennum et al. 1989, Tang 1995, Brusseau et al. 2003). BNL has also developed methods for seven perfluorinated tracer compounds (PFTs) as non-reactive tracers in numerous applications from atmospheric transport to underground leak detection (Watson et al. 2007). PFTs should serve as effective geothermal tracers because they are physically and chemically stable, detectable at very low concentrations, and have extremely low background levels.

The project will develop and apply models for describing interactions of tracers with EGS reservoirs in various tracer test configurations. The modeling work will extend the theoretical framework that is already used successfully in groundwater applications. Forward modeling will be employed for selecting tracers by identifying optimal thermal and surface adsorption properties for geothermal applications, and will also be used to evaluate the potential effectiveness of experimentally determined tracer properties in geothermal settings. Integrating modeling with laboratory experiments will make certain that models are 
improved and validated by the experimental data and that experiments address key modeling needs. Inverse modeling will be used to interpret field tracer transport behavior, providing a method to estimate reservoir properties and their uncertainties.

The purpose of this report is to describe the simulation plan and status of model development for simulating single- and multi-well tracer tests for characterizing EGS. This report contains a description of the simulation requirements, selected codes, code testing, and examples of preliminary scoping results for both numerical and analytical simulations. Following the initial model development for scoping simulations, models will be built based on laboratory testing of candidate tracers for potential field test sites. Once a field site has been selected, design analysis simulations will be conducted to guide site layout (i.e., design of monitoring well network) and field test operations (i.e., injection rate, volume, shutin period, withdrawal rate). Lastly, simulations will be used to interpret the field test results. 


\subsection{Simulation Requirements}

This section describes the features and capabilities required for simulating single- and multi-well tracer tests targeted at characterizing EGS. The selection and development of numerical and analytical codes, along with procedures for code testing, are also discussed.

\subsection{Simulator Capabilities}

The geothermal systems simulated as part of this project are assumed to be saturated, single-phase aqueous systems (i.e., no gas/steam phase). In addition to water flow, the codes to be used for simulating tracer transport must account for energy transport (conduction and advection) and mass transport (advection, dispersion, and diffusion) as well as relevant couplings between mass and energy transport (for thermally degrading tracers). At this time, we do not anticipate the need for simultaneous mechanical stress calculations coupled with mass and energy transport calculations (e.g., mechanical opening of fractures and resultant changes in fracture SA/V ratio as a result of cooling of the rock mass) because these effects will be treated as unknowns that will be interrogated by the tracers. Additional solute transport requirements for simulating reactive tracers are discussed below. Requirements for simulating fractures and well functions are also discussed below.

\subsubsection{Solute Reactions}

Simulating the transport behavior of a suite of tracers for EGS reservoir characterization may require the ability to simulate tracer sorption, thermal degradation, diffusion, and possible reaction of a tracer to form reaction products. The types of tracer transport behavior to be simulated, along with the required parameters, will depend on the results of laboratory or relevant field experiments. Initial scoping simulations of differing transport behavior will be conducted over a range of property values to help guide laboratory experiments and identify properties that would be helpful in characterizing EGS.

Tracer sorption could include equilibrium sorption with a linear isotherm $\left(\mathrm{K}_{\mathrm{d}}\right)$. More complex sorption reactions, such as non-equilibrium or non-linear isotherms (e.g., Freundlich or Langmuir nonlinear isotherms), may be needed, depending on results of laboratory experiments for candidate tracers.

Tracer degradation could include simple constant first-order decay (i.e., half-life) or more complex thermally degrading tracers as described by Adams and Davis (1991) and Rose and Adams (1994). The behavior of thermally degrading tracers has been modeled by the above authors for Fluorescein and Rhodamine tracers using the Arrhenius equation:

$$
k=A e^{-E_{a} / R T}
$$

where $\quad K=$ rate coefficient $(1 / \mathrm{s})$

$A=$ pre-exponential constant $(1 / \mathrm{s})$

$E_{a}=$ activation energy $(\mathrm{J} / \mathrm{mol})$

$R=$ ideal gas constant $\left(8.314 \times 10^{-3} \mathrm{~kJ} /(\mathrm{mol} \cdot \mathrm{K})\right)$

$T=$ temperature $(\mathrm{K})$. 
Another type of tracer that could be useful in characterizing EGS is a thermally stable solute that is encapsulated in a submicron-diameter shell that can undergo thermal degradation, thereby releasing the solute when the particle experiences a time-temperature history that causes the shell to breach. The encapsulation of PFTs will be investigated as part of the laboratory experiments for this project.

Modifications to the existing codes are required to simulate the transport of submicron solutes and release of encapsulated tracers at a threshold temperature based on the results of these laboratory tests.

\subsubsection{Fractures}

Fracture/fault characteristics of density, spacing, and, more importantly, the SA/V ratio are key parameters for understanding fluid flow and heat transfer in EGS reservoirs. The tracers and tracer tests will be designed to interrogate the subsurface to obtain information on these unknown parameters. Thus, the simulators used for tracer test design and interpretation must not be excessively constrained by assumptions about fracture/fault geometry to avoid introducing biases into the designs or interpretations. Relatively simple representations of fracture networks, such as the use of characteristic fracture apertures and fracture spacings, have been used in previous studies and are probably sufficient for achieving design and interpretation objectives (this assumption will be evaluated).

O'Sullivan et al. (2001) surveyed a broad range of researchers that had simulated geothermal reservoirs at locations around the globe. Based on the results of this survey, fractures and fracture networks have been simulated as either discrete fracture networks or with dual-porosity/dual-continuum models (e.g., Warren and Root 1963). For simulating discrete fracture networks, subgridding or irregular gridding techniques have been used to reduce the grid size and computational requirements of the problem (see O'Sullivan et al. 2001 for examples). Dual-porosity representations of fractures have been used extensively in geothermal simulations because of lower computational requirements (e.g., Pruess and Narasimhan 1982) and the general uncertainty in fracture network characterization.

\subsubsection{Well Operations}

The ability of a code to represent wells is important because the introduction and sampling for tracers will generally occur via such subsurface penetrations. Typically, in the code, the well injection/withdrawal flow rates can be specified directly, rather than requiring knowledge of the time course of well pressures. The capability of a code to calculate vertically variable fluxes across a well screen (given a total discharge amount) because of permeability heterogeneities is also important. However, well functions are difficult to implement in variable density systems because of the nonlinearity of the problem, for which solution convergence can be difficult.

Codes that provide grids with two-dimensional radial symmetry are needed to simulate single-well injection/withdrawal simulations with relatively simple hydrostratigraphy, such as will be used in initial scoping calculations. Multiple injection/withdrawal wells or complex hydrostratigraphy/heterogeneities cannot be accurately simulated with two-dimensional radially symmetric grids and will require developing three-dimensional model domains. 


\subsection{Numerical Codes}

This section describes the numerical codes that are being considered for use in simulating injection/withdrawal tracer tests in EGS. Semi-analytical codes developed for this effort are described in Sections 4 and 5. Two numerical codes, Subsurface Transport Over Multiple Phases (STOMP) and TOUGHREACT, are described below as candidates for use in simulating tracer tests in EGS. Additional codes that may be considered in the future for use in this project are FEHM (developed at LANL) and PFLOTRAN (also developed at LANL).

The STOMP code was selected because it had many of the capabilities described in Section 2.1, it was familiar to some of the researchers on this project, and the source code is available for customization. In addition to the STOMP code, the TOUGHREACT code will also be considered for use in this project because of its capabilities and because of the wide adoption of this code by geothermal researchers (as discussed below).

\subsubsection{STOMP}

The STOMP code is a finite difference, multi-fluid, flow and transport code developed by Pacific Northwest National Laboratory (PNNL) (White and Oostrom 2000, 2006) and is described online at the following site: http://stomp.pnl.gov. The code has multiple operational modes that support certain combinations of energy transport, non-aqueous phase liquids (NAPLs), gases, and water. STOMP has been enhanced in recent years for use in supercritical $\mathrm{CO}_{2}$ injection simulations for assessing green house gas sequestration. STOMP has a dual-continuum feature that can be used to represent fractures (implemented in selected modes), but does not currently have a non-equilibrium dual continuum capability implemented in the energy modes. The STOMP well function is also not currently implemented in the energy mode. Adding the STOMP well function to the energy mode is a planned future activity.

As part of this project, a thermal degradation function for tracers using the Arrhenius equation (as described above) was recently implemented in STOMP. Currently, the STOMP code can be used for simulating injection/withdrawal tests for thermally degrading tracers (see example Section 3). The STOMP code also accommodates two-dimensional radially symmetric grids that are efficient (compared to three dimensional grids) for simulating single-well injection/withdrawal tests. Discrete fractures can be simulated with high-resolution, variable grid spacing around fracture zones, and higher permeability can be applied to represent the fractures.

\subsubsection{TOUGHREACT}

TOUGH2 (Pruess et al. 1999) and the updated version for reactive transport, TOUGHREACT (Xu 2006), have been used for simulating geothermal systems in a large number of sites (e.g., O'Sullivan et al. 2001). TOUGH 2 and TOUGHREACT use an integrated finite-difference approach that provides for unstructured grids. In addition to fluid, solute, and energy flow, TOUGH2 and TOUGHREACT provide a multiple interacting continua (MINC) method for simulating fractures (see Pruess 1983 and 1992), which is an extension of the dual-porosity method described by Warren and Root (1963). The survey of geothermal simulations by O'Sullivan et al. (2001) showed that many sites have applied the MINC 
method for simulating fracture systems. Fayer et al. (2009) have used TOUGHREACT with the MINC method for simulating thermally degrading tracers in injection tests.

The TOUGHREACT code is currently being evaluated for use in this project for simulating injection/withdrawal tests of thermally degrading tracers. Scoping simulations with the TOUGHREACT code for this project have not yet been conducted.

\subsubsection{Code Testing}

Initial general testing of the numerical codes used in this study will be conducted by comparing results to the energy-transport test cases provided with the codes. For the STOMP code, this includes the heat-pipe test case, which also has an analytical solution. TOUGH2 and TOUGHREACT also provide several geothermal/energy transport test cases with the software distribution. Additionally, simulations will be conducted using the water-dominated geothermal test cases developed during the DOE Model Intercomparison Study (DOE 1980). Additional software testing requirements will be developed (including documented test cases) for features and changes added to the numerical codes as part of this project. 


\subsection{STOMP Numerical Simulations}

This section describes some example simulations using the STOMP code with the water, air, and energy mode. A non-equilibrium, dual continuum model has not been implemented in the energy modes of STOMP, so discrete fractures were simulated with grid refinements as described below.

The initial STOMP simulations were developed for scoping to investigate single-well injection/withdrawal tests with thermally degrading tracers. Two-dimensional, radially symmetric, finite difference grids were constructed with the grid refined around discrete horizontal and vertical fractures. These grids had a $0.25-\mathrm{m}$ horizontal node spacing near the injection/withdrawal well (0 to $50 \mathrm{~m}$ ) with larger grid spacing toward the outer radial boundary (from 50 to $500 \mathrm{~m}$ ) as shown in Figure 3.1. Vertical grid spacing ranged from $0.001 \mathrm{~m}$ within and adjacent to the fracture zone, grading to $0.25 \mathrm{~m}$ away from the fracture zone. Simulations were initially constructed with multiple horizontal and vertical fractures; however, the computational requirements for running these simulations with the large number of nodes needed to resolve these multi-fracture simulations were excessive, so single-fracture simulations were constructed. Different horizontal fracture spacing can be investigated with these single-fracture simulations by adjusting the domain.

\subsection{Material Properties}

As shown in Figure 3.2, two zones were created representing the bedrock zone for most of the domain and a thin, higher permeability zone at the bottom representing a horizontal fracture. For the example case described in this section, the bedrock zone permeability was set at $1.5 \times 10^{-3}$ darcy with the fracture zone permeability 10,000 times greater at 15 darcy. Additionally, the porosity of the bedrock zone was set at $10 \%$ with the fracture zone porosity greater at $40 \%$. Other material properties used in this simulation are reported in Table 3.1.

\subsection{Tracers}

Three different tracers were set up for these simulations, designated as T1, T2, and T4. All three tracers are non-sorbing with aqueous molecular diffusion rates of $7.8 \times 10^{-10} \mathrm{~m}^{2} / \mathrm{s}$ at $20^{\circ} \mathrm{C}$. Longitudinal dispersivity for these tracers was set to $0.2 \mathrm{~m}$ and $0.02 \mathrm{~m}$ transverse dispersivity. Tracer $\mathrm{T} 1 \mathrm{is} \mathrm{a}$ conservative tracer with no decay. Tracer $\mathrm{T} 2$ has a constant first-order decay rate with a half-life of 0.5 years. Tracer $\mathrm{T} 4$ is a synthetic, thermally degrading tracer with the Arrhenius constants selected to yield a 0.5 -year half life at $200^{\circ} \mathrm{C}$. The Arrhenius parameters for tracer T4 are $\mathrm{k}=2.9 \times 10^{8} 1 / \mathrm{s}$ and $\mathrm{A}_{\mathrm{e}}=1.433 \times 10^{5} \mathrm{~J} / \mathrm{mol}$.

\subsection{Boundary Conditions}

The top and bottom of the simulation domain were set to no-flow conditions for fluid, heat, and solutes. At the bottom of the innermost $(\mathrm{R}=0)$ and outermost $(\mathrm{R}=500 \mathrm{~m})$ boundaries, the pressures were initially set to $20 \mathrm{MPa}$ to represent fluid pressures at approximately $2 \mathrm{~km}$ depth. Pressures on the sides of the domain were calculated at hydrostatic pressures from the $20.0 \mathrm{MPa}$ specified base pressure.

Temperatures on the inner and outer boundaries, and within the domain, were initially set to $200^{\circ} \mathrm{C}$. The 
pressures and temperatures for these simulations were chosen so that the water would be in the liquid phase only.

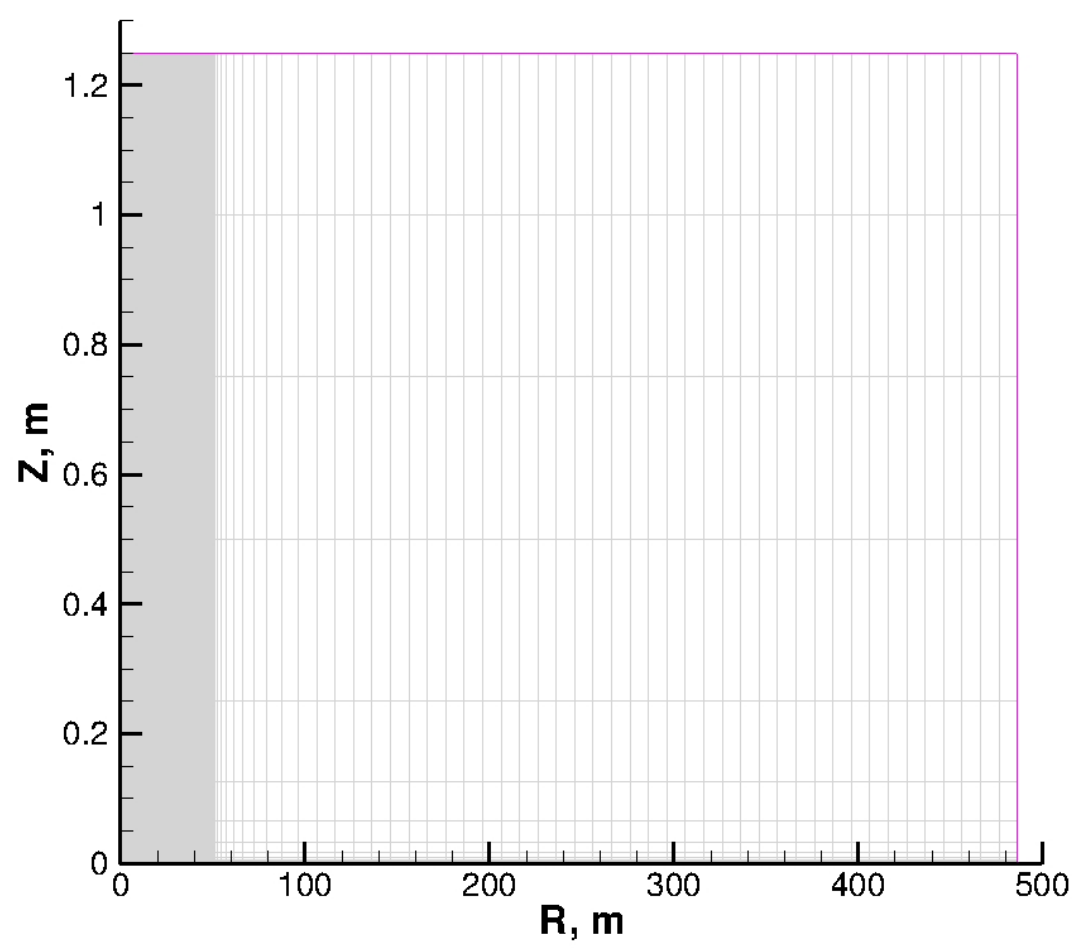

Figure 3.1. Two-Dimensional, Radially Symmetric, Finite Difference STOMP Grid. The grid is refined near the injection/withdrawal well ( $\mathrm{R}=0$ to $50 \mathrm{~m}$ ) boundary and along the bottom (to represent a horizontal fracture zone). See Figure 3.2 also.

\subsection{Initial Conditions}

Initial temperatures within the domain were set to $200^{\circ} \mathrm{C}$, and all tracer concentrations were set to zero. Initial pressures were calculated from the results of a quasi-steady state run using the boundary value pressures described above.

\subsection{Operational/Transient Conditions}

The simulation was configured for an initial 30-day injection period with pressures specified on the injection well side of the domain $(\mathrm{R}=0)$ calculated from a base pressure of $20.1 \mathrm{MPa}$. The injection temperature was cooler than the formation fluid and set to $150^{\circ} \mathrm{C}$. Injection concentrations of the tracers were set to 1 . Following the injection period was a 30 -day shut-in period with the boundary condition at the injection side $(\mathrm{R}=0)$ set to no-flow for fluid, temperature, and solutes. A 30-day withdrawal period was started at the end of the shut-in period (elapsed simulation time of 60 days) with pressures set on the injection well side of the domain calculated from a base pressure of $19.9 \mathrm{MPa}$. Fluid temperatures entering the outermost boundary $(\mathrm{R}=500 \mathrm{~m})$ during the withdrawal period were set to $200^{\circ} \mathrm{C}$, and the inflowing solute concentrations were set to zero. 


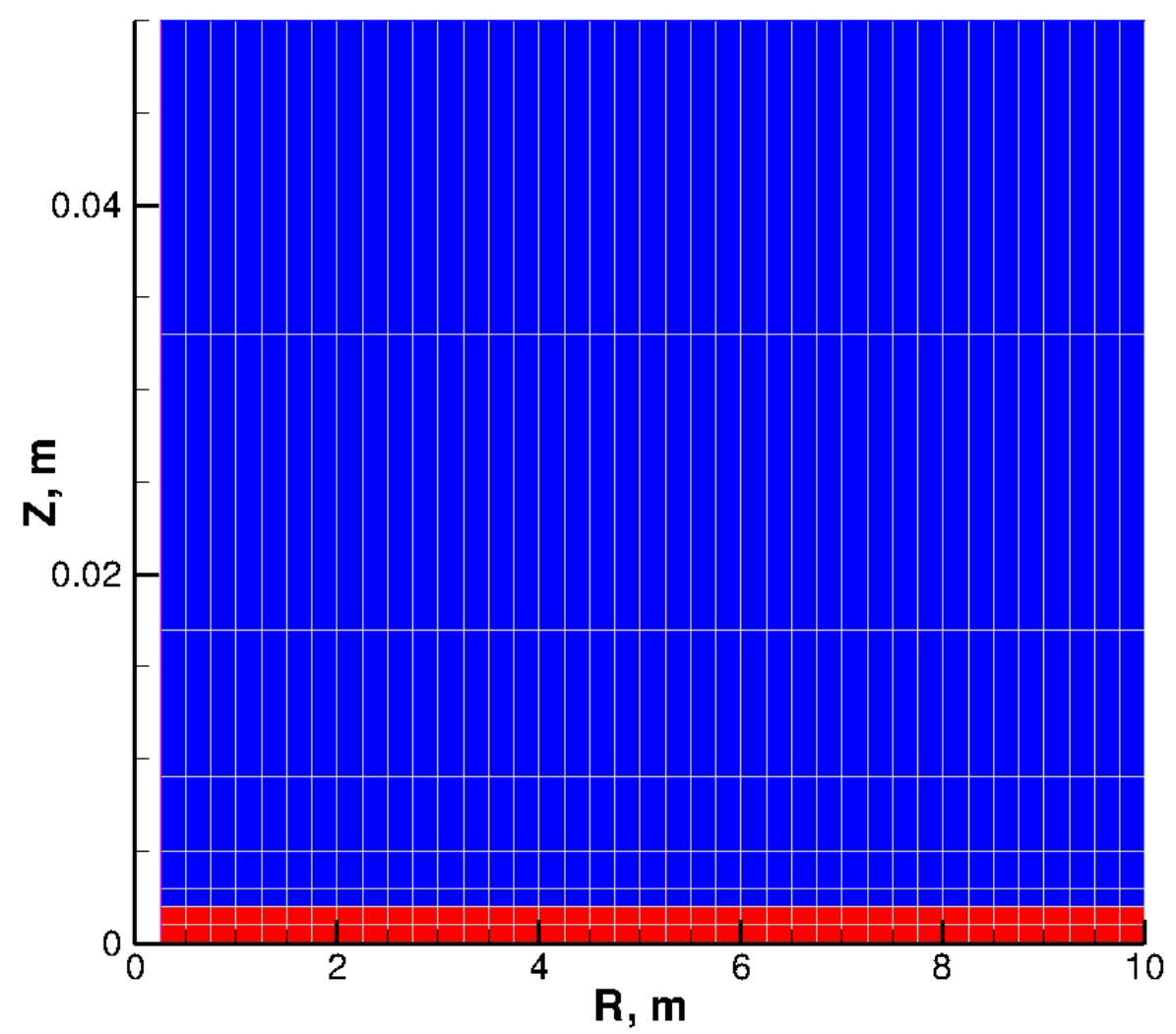

Figure 3.2. Zoomed View of the Two-Dimensional, Radially Symmetric, Finite Difference STOMP Grid. The blue color is the bedrock zone, and the red color is the fracture zone.

Table 3.1. Material Properties Used in the Example Simulation

\begin{tabular}{|c|c|c|c|c|c|}
\hline Zone & $\begin{array}{l}\text { Permeability } \\
\text { (isotropic) }\end{array}$ & Porosity & $\begin{array}{l}\text { Rock } \\
\text { Compressibility }\end{array}$ & $\begin{array}{l}\text { Thermal } \\
\text { Conductivity } \\
\text { (isotropic) }\end{array}$ & Specific Heat \\
\hline Bedrock & $1.5 \times 10^{-3}$ darcy & 0.10 & $1.0 \times 10^{-9} 1 / \mathrm{Pa}$ & $3.3 \mathrm{~W} /(\mathrm{m} \mathrm{K})$ & $816 \mathrm{~J} /(\mathrm{kg} \mathrm{K})$ \\
\hline Fracture & 15 darcy & 0.40 & $1.0 \times 10^{-9} 1 / \mathrm{Pa}$ & $3.3 \mathrm{~W} /(\mathrm{m} \mathrm{K})$ & $816 \mathrm{~J} /(\mathrm{kg} \mathrm{K})$ \\
\hline
\end{tabular}

\subsection{Simulation Results}

Figure 3.3 shows the simulated temperature field results at selected times for the injection ( 0 to 30 days), shut-in (30 to 60 days), and withdrawal (60 to 90 days) periods. Concentrations for the conservative tracer (T1) for these times are shown in Figure 3.4. Simulated concentrations for the tracer (T2) with a constant 0.5-year, half-life are shown in Figure 3.5, and the simulated concentrations for the tracer (T4) undergoing temperature-dependent (Arrhenius) degradation are shown in Figure 3.6.

A trend plot showing tracer concentrations within the well and the well flux rates is shown in Figure 3.7 for the three operational periods (injection, shut-in, withdrawal). Since a constant pressure 


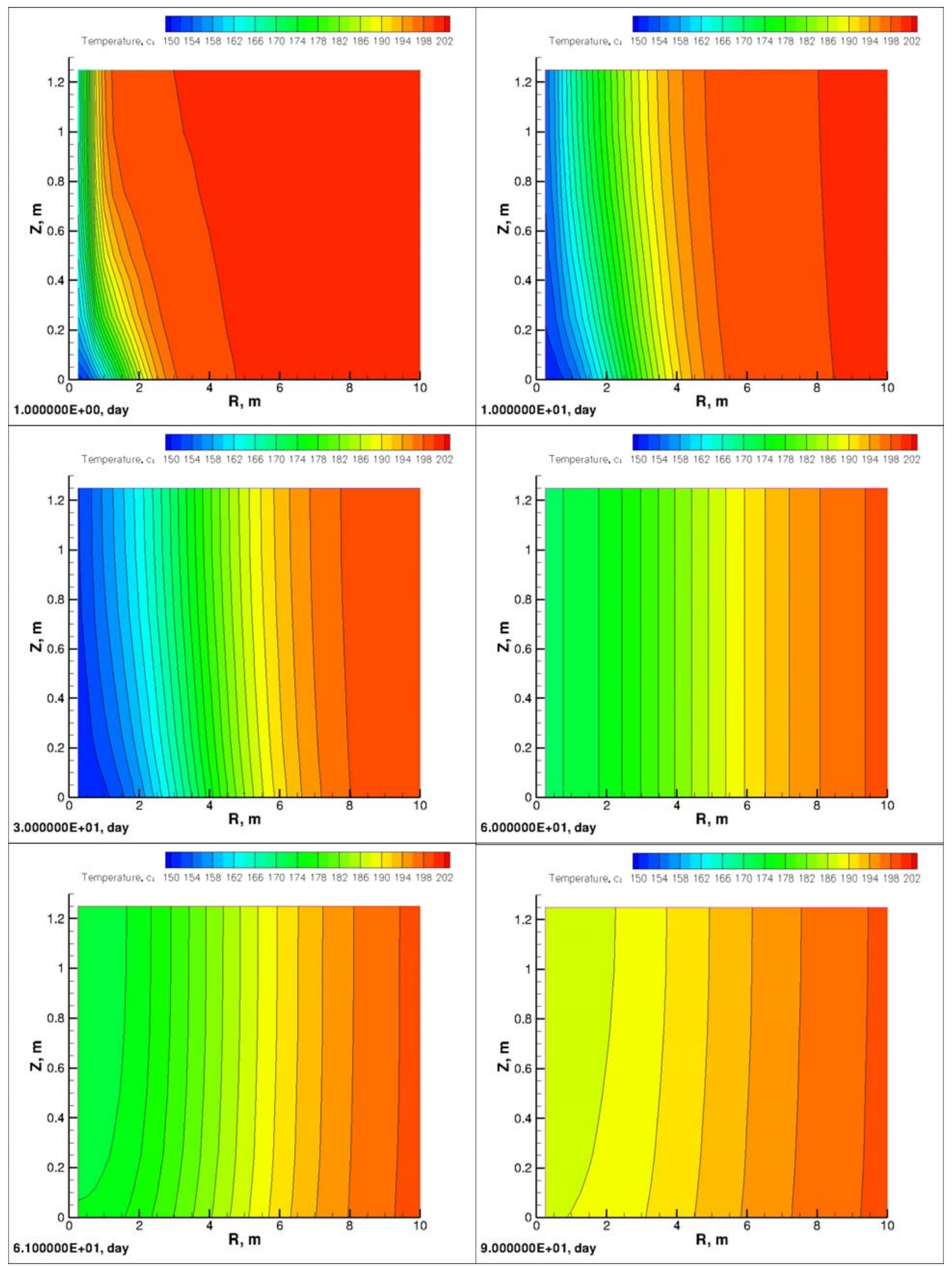

Figure 3.3. Simulated Temperatures for an Example Single-Well Injection/Shut-in/Withdrawal Test 


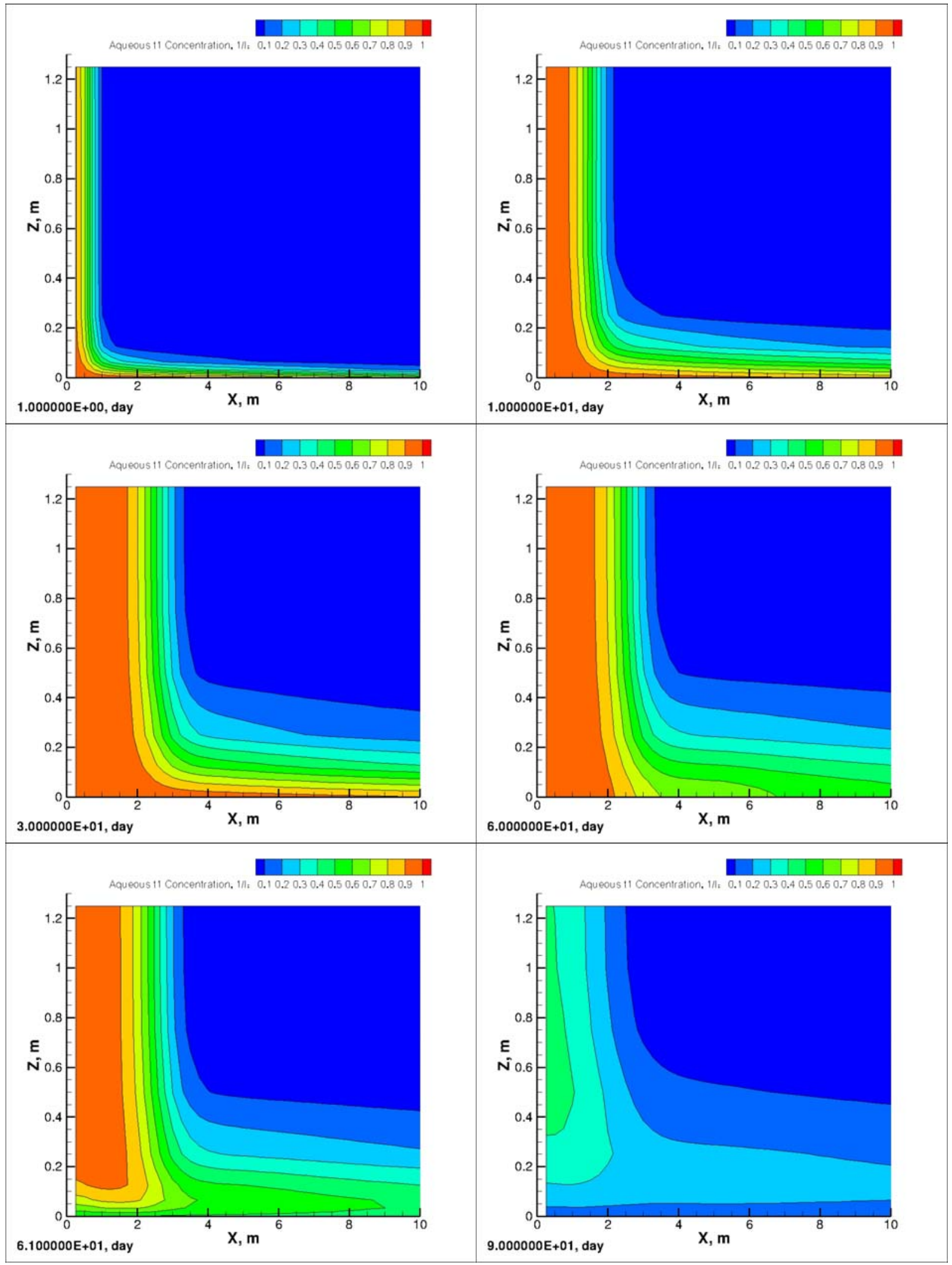

Figure 3.4. Simulated Conservative Tracer for an Example Single-Well Injection/Shut-in/Withdrawal Test 


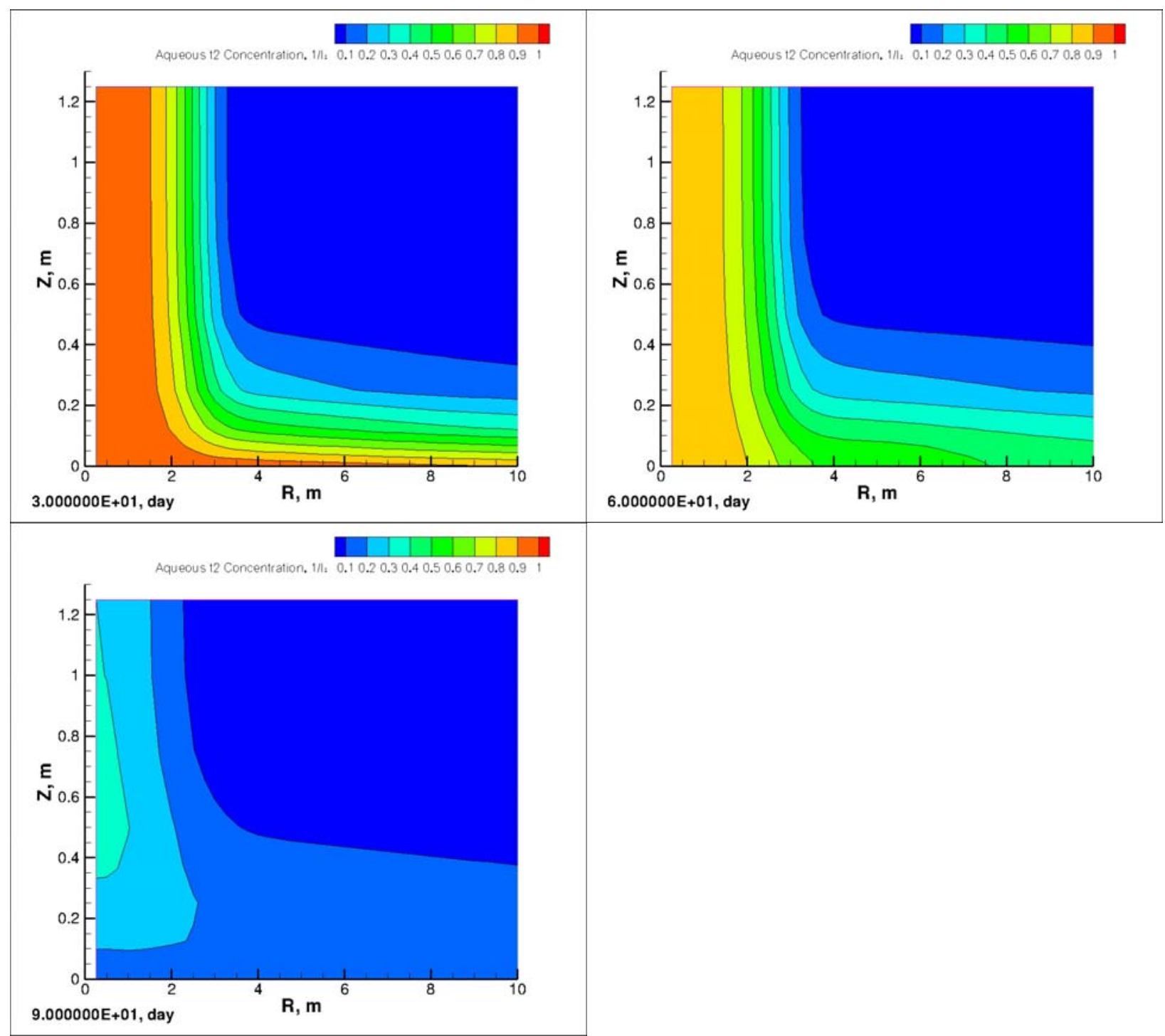

Figure 3.5. Simulated Tracer with Constant Half-Life for an Example Single-Well Injection/Shutin/Withdrawal Test 


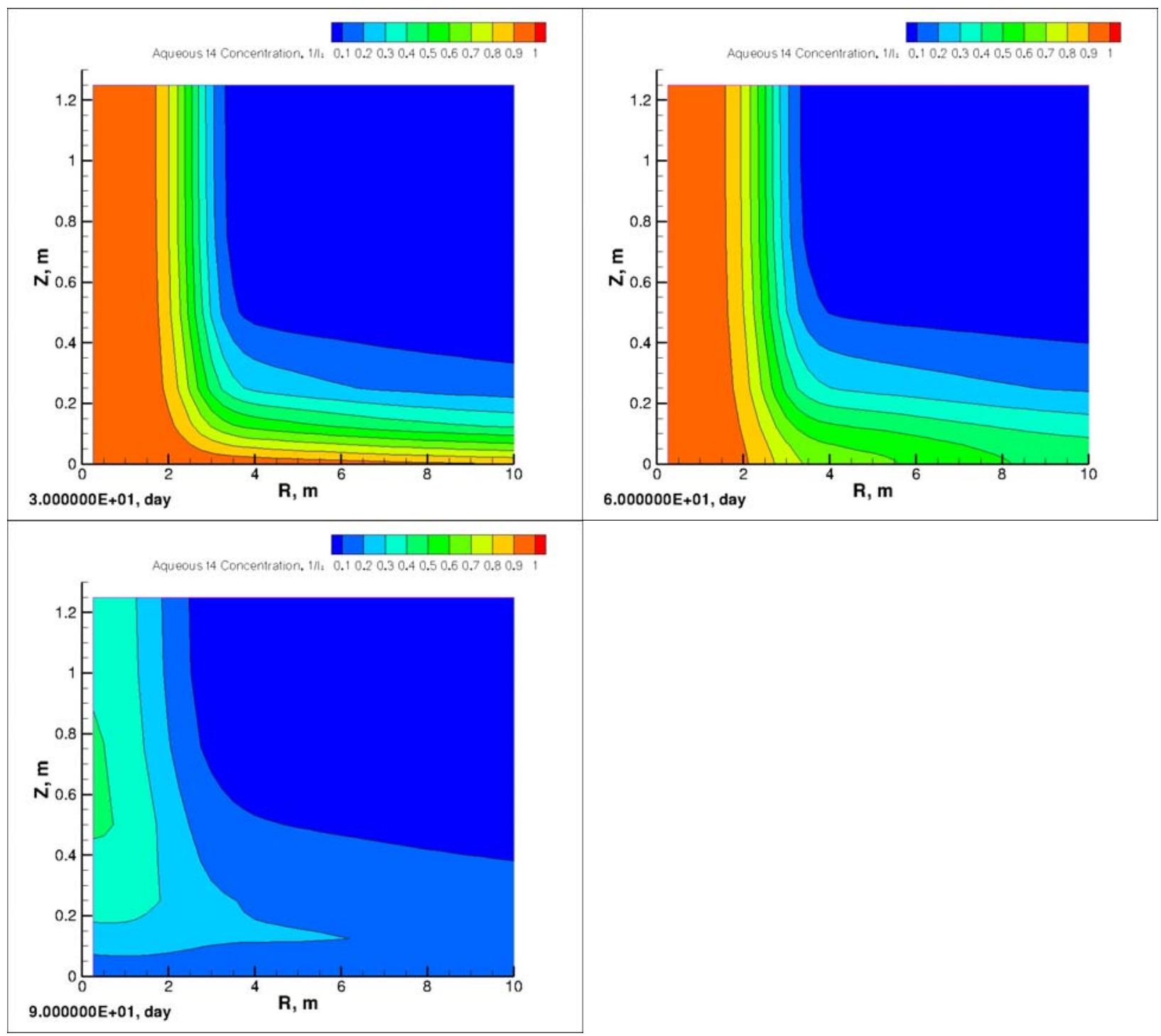

Figure 3.6. Simulated Tracer with Temperature-Dependent Degradation for an Example Single-Well Injection/Shut-in/Withdrawal Test 


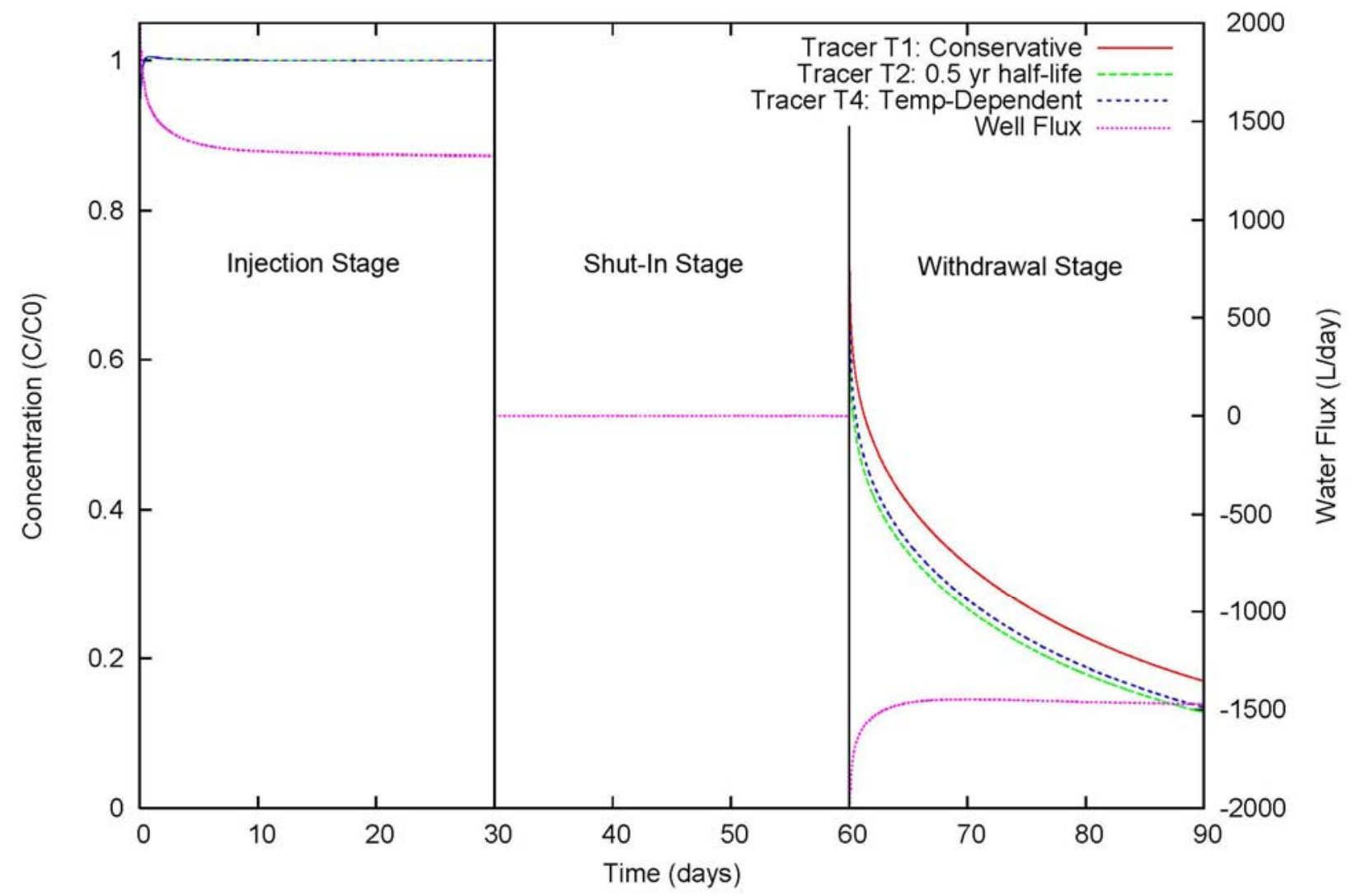

Figure 3.7. Plot of Simulated Well Concentrations and Injection/Withdrawal Rates for a Single-Well Injection/Withdrawal Test

boundary condition is used to simulate a well, the well flux rates take a while to stabilize during the start of the injection and withdrawal stages (see Figure 3.7). Applying temporal changes in the boundary pressures would achieve a more uniform flux rate without using a well model. Additionally, the injection rates are slightly lower than the withdrawal rates with these boundary pressures. Because there is not a well function built into the energy mode for STOMP, these pressures can be adjusted based on a few trial and error runs with the same material properties and boundary pressures. Adding the well function into the energy mode of STOMP is being planned.

Figure 3.8 and Figure 3.9 show simulated tracer concentrations and temperatures for nodes within the model domain during the injection, shut-in, and withdrawal stages. The node locations were selected within the fracture zone $(\mathrm{Z}=0 \mathrm{~m})$ and at the furthest distance away from the fracture zone $(\mathrm{Z}=1.125)$ near the upper model boundary. Figure 3.8 shows the results near the injection/withdrawal well $(\mathrm{R}=0.375 \mathrm{~m})$ and Figure 3.9 shows the results $2.625 \mathrm{~m}$ away from the injection/withdrawal well.

The computational requirements for these STOMP simulations with discrete factures in a single injection/withdrawal well operation are long (e.g., weeks for a single run) because of the small time steps required for convergence. The majority of the run time is consumed during the simulation of the first few days because of the steep temperature gradients near the injection/withdrawal well. Larger time steps can be taken during the later portion of the simulation period. 


\subsection{Additional STOMP Simulations}

Additional STOMP simulations with discrete fractures and this general model configuration will be conducted for assessing the impact of different fracture apertures, fracture spacing, and tracer degradation rates. Results from these STOMP simulations will be compared to other simulations that are being developed using dual-continuum models for fractures and using other codes (e.g., TOUGHREACT and the semi-analytical models discussed in Sections 4 and 5). Based on a comparison of the results and computational requirements of the simulations, codes and simulations will be selected for use in the initial screening of various tracers. Multi-well simulations will also be constructed using three-dimensional model domains.

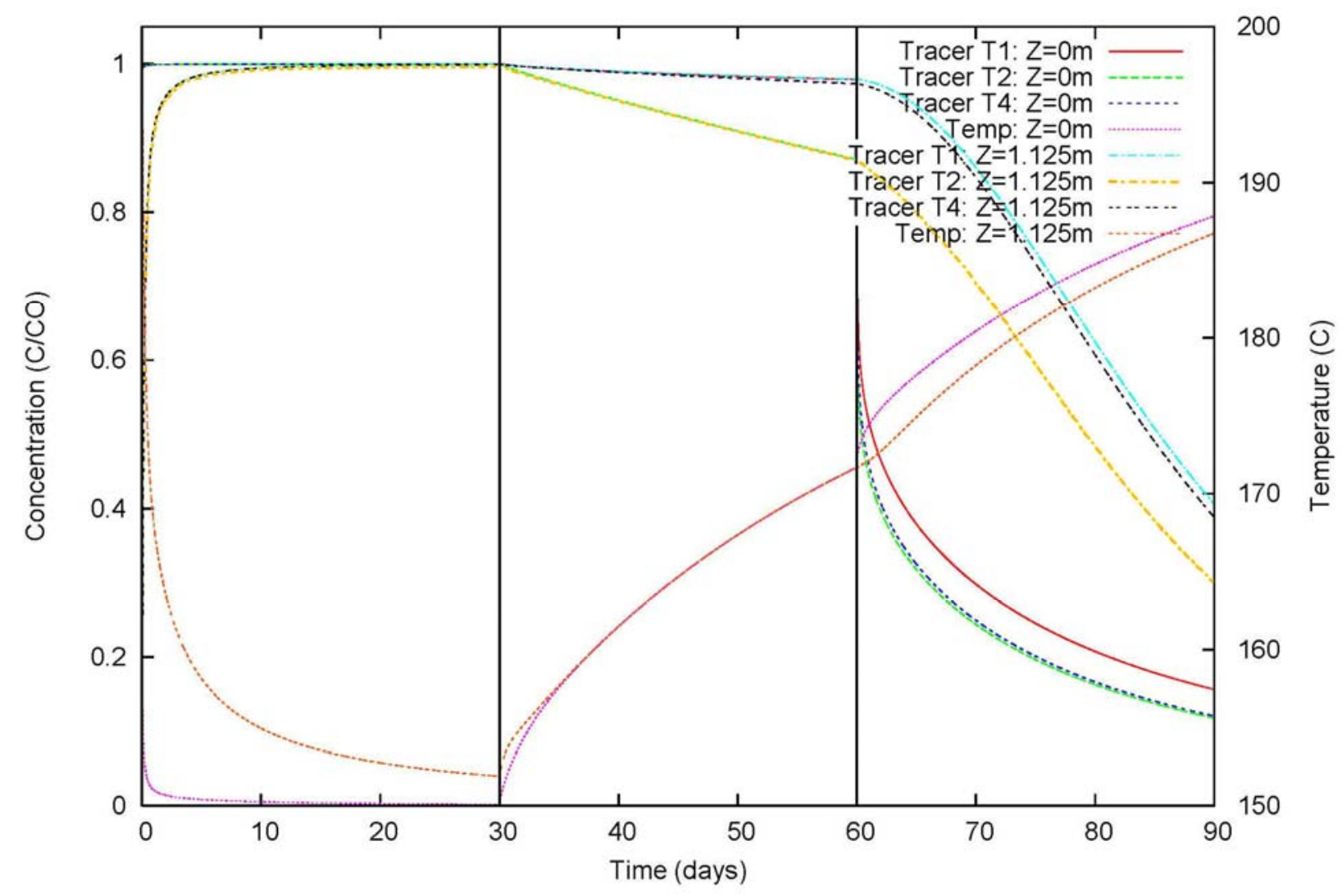

Figure 3.8. Simulated Tracers and Temperatures for an Injection/Shut-in/Withdrawal Test. Results are for near-well nodes at $\mathrm{r}=0.375 \mathrm{~m}$ within the fracture zone $(\mathrm{z}=0 \mathrm{~m})$ and at the top of the domain $(\mathrm{z}=1.125 \mathrm{~m})$. 


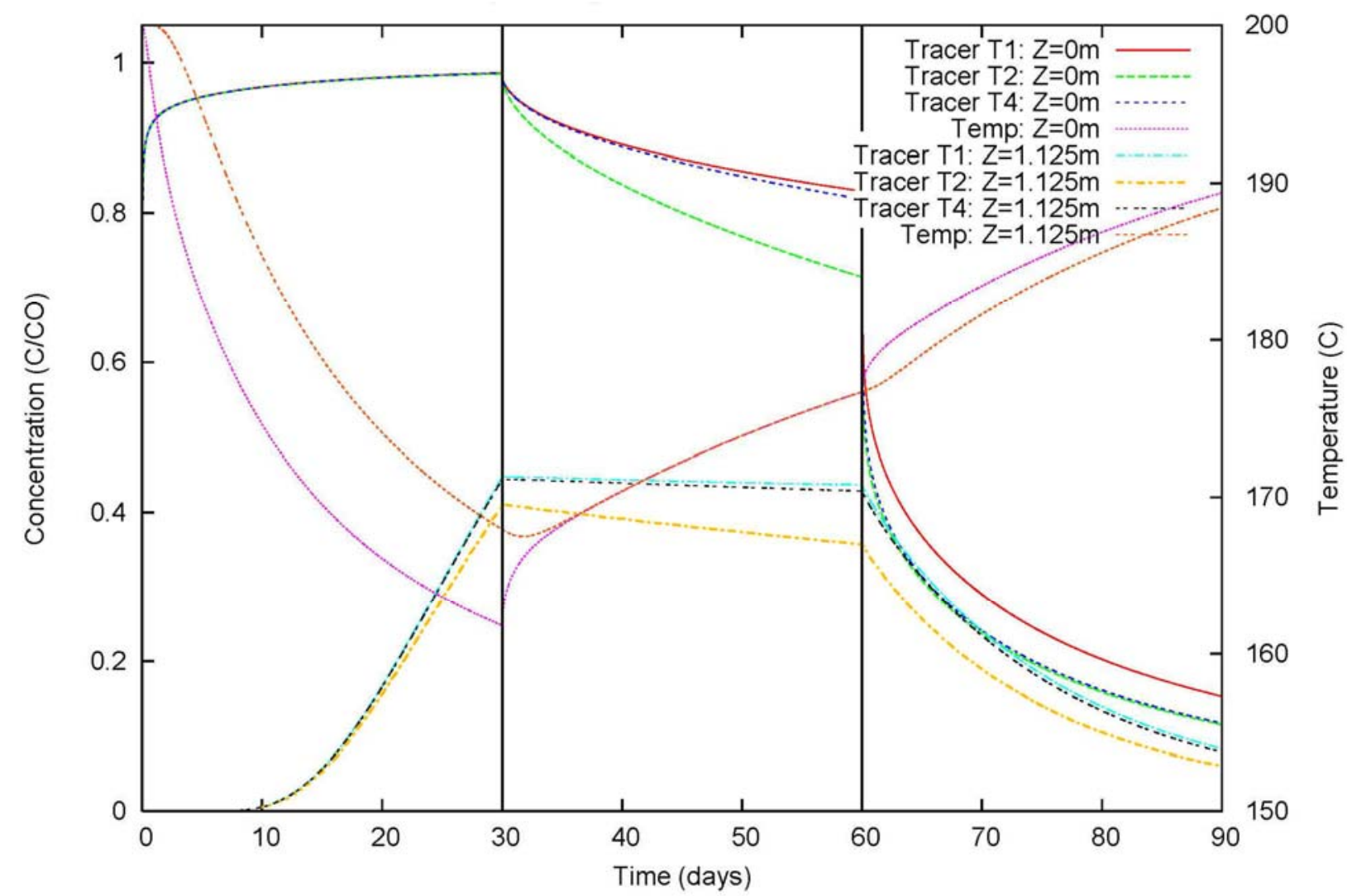

Figure 3.9. Simulated Tracers and Temperatures for an Injection/Shut-in/Withdrawal Test. Results are for nodes at $\mathrm{r}=2.625 \mathrm{~m}$ within the fracture zone $(\mathrm{z}=0 \mathrm{~m})$ and at the top of the domain $(\mathrm{z}=1.125 \mathrm{~m})$. 


\subsection{Semi-Analytical Model Simulations}

\subsection{Thermally Degrading Tracers to Predict Thermal Breakthrough}

A semi-analytical model was developed to conduct rapid scoping calculations of responses of thermally degrading tracers in multi-well tracer tests in EGS. The model is based on the Reactive Transport Laplace Inversion (RELAP) computer model for solute transport in dual-porosity media (Reimus et al. 2003). The RELAP model combines the Laplace-domain dual-porosity transport equations derived by Maloszewski and Zuber (1984, Appendix; 1985) with Laplace-domain transfer functions that describe a finite-pulse injection, wellbore mixing, and recirculation (although the latter two features were not used here). It can also simulate linear, reversible sorption (either rate-limited or equilibrium). Maloszewski and Zuber (1984, Appendix; 1985) assumed that tracer transport in fractures was described by the one-dimensional advection-dispersion equation with one-dimensional diffusion occurring into the surrounding matrix perpendicular to the flow direction in fractures. The model assumes 1) parallel-plate fractures of constant aperture, $2 \mathrm{~b}$, and either constant spacing, $L$, or infinite spacing (a semi-infinite matrix), 2) no concentration gradients across the fracture aperture, and 3) a steady flow rate in fractures. The most restrictive of these assumptions for EGS is the steady flow-rate assumption, which makes it impossible to simulate single-well tracer tests involving flow reversals.

The equations describing dual-porosity transport of a non-reactive tracer under the conditions described above are (based on Maloszewski and Zuber [1984, Appendix]):

Fracture:

$$
\frac{\partial C}{\partial t}+V \frac{\partial C}{\partial x}-D \frac{\partial^{2} C}{\partial x^{2}}-\left.\frac{\phi_{m}}{b} D_{m} \frac{\partial C_{m}}{\partial y}\right|_{y=b}=0
$$

Matrix:

$$
\frac{\partial C_{m}}{\partial t}-D_{m} \frac{\partial^{2} C_{m}}{\partial y^{2}}=0
$$

where $\quad C=$ solute concentration in fractures or flowing porosity, $\mathrm{g} / \mathrm{cm}^{3}$

$C_{m}=$ solute concentration in matrix or nonflowing porosity, $\mathrm{g} / \mathrm{cm}^{3}$

$V=$ mean water velocity in fractures, $\mathrm{cm} / \mathrm{s}$

$D=$ solute dispersion coefficient in fractures, $\mathrm{cm}^{2} / \mathrm{s}$

$\phi_{\mathrm{m}}=$ matrix porosity

$b=$ fracture half-aperture, $\mathrm{cm}$ (fractures assumed to have an internal porosity of 1.0)

$D_{m}=$ solute diffusion coefficient in matrix, $\mathrm{cm}^{2} / \mathrm{s}$

$x=$ coordinate in flow direction

$y=$ coordinate in diffusion direction, and

$t=$ time, $\mathrm{s}$.

Additional terms are required in Equations (4.1) and (4.2) to describe reactive tracer transport. For a thermally degrading tracer, the term $-k C$ must be added to left side of Equation (4.1), and the term $-k C_{m}$ must be added to the left side of Equation (4.2), where $k$ is the decay constant given by Equation (2.1). The transformation of Equations (4.1) and (4.2) to the Laplace domain and their subsequent Laplacedomain solution and inversion of the result back to the time domain are described by Reimus et al. (2003). 
Note that Equations (4.1) and (4.2) reduce to a single-porosity system if the matrix porosity, $\phi$, (or the matrix diffusion coefficient, $\left.D_{\mathrm{m}}\right)$ is set equal to zero.

The heat-transfer model developed for this report takes advantage of the analogies between heat and mass transport. Equations (4.1) and (4.2) for heat transfer in a dual-porosity system are:

Fracture:

$$
\left(\rho C_{p}\right)_{w}\left(\frac{\partial T}{\partial t}+V \frac{\partial T}{\partial x}-D \frac{\partial^{2} T}{\partial x^{2}}\right)-\left.\frac{k_{m}}{b} \frac{\partial T_{m}}{\partial y}\right|_{y=b}=0
$$

Matrix:

$$
\left(\rho C_{p}\right)_{m} \frac{\partial T_{m}}{\partial t}-k_{m} \frac{\partial^{2} T_{m}}{\partial y^{2}}=0
$$

where $\quad T=$ temperature in fractures or flowing porosity, $\mathrm{K}$

$T_{m}=$ temperature in matrix, $\mathrm{K}$

$\rho=$ density (water or matrix), $\mathrm{g} / \mathrm{cm}^{3}$ (subscript $w$ for water, $m$ for matrix)

$C_{p}=$ heat capacity (water or matrix), cal $/ \mathrm{g}-\mathrm{K}$ (subscript $w$ for water, $m$ for matrix)

$k_{m}=$ thermal conductivity of matrix, cal/cm-s-K.

Note that in Equations (4.3) and (4.4), it is understood that the matrix values of $\rho, C_{p}$, and $k_{m}$ will depend on the matrix porosity; i.e., these values can be approximated from $X_{m}=\phi X_{w}+(1-\phi) X_{r}$, where $X$ is a general property $\left(\rho, C_{p}\right.$, or $\left.k_{m}\right)$ and $X_{r}$ denotes the value of the property for the rock.

The analogies between Equations (4.3) and (4.4) and Equations (4.1) and (4.2) are obvious, and a solution for temperature in Equations (4.3) and (4.4) can be readily obtained from a solution for concentration in Equations (4.1) and (4.2) by simply substituting $k_{m} /\left(\rho C_{p}\right)_{w}$ for $\phi D_{m}$ in Equation (4.1) and $k_{m} /\left(\rho C_{p}\right)_{m}$ for $D_{m}$ in Equation (4.2). This is exactly what was done to obtain a temperature solution using the existing RELAP concentration solution.

RELAP is not capable of providing a true simultaneous solution of temperature and concentration because the Laplace-domain algorithm only solves for one variable at a time while all other variables are held constant. However, since heat transfer in EGS has essentially no dependence on solution concentrations, it is acceptable to first obtain a temperature solution and then obtain a concentration solution that includes the temperature dependence of tracer thermal decay. The Laplace-domain algorithm also provides a temperature or concentration solution only at the exit of the simulated domain, so spatial variability in temperature must be obtained by dividing the domain into discrete segments, each of which has a separate temperature solution. A consistent overall temperature solution is obtained by linking the segments together by convolution, which is achieved in the Laplace domain by simple multiplication of the transfer functions for each individual segment. Once a spatial temperature profile is obtained (at a given point in time), a tracer transport solution can be obtained by similarly linking together segments and using the temperature calculated for each segment to determine the temperature-dependent decay rate constant in each segment. This approach involves the following assumptions:

- The temperature within each segment is assumed constant (equal to the exit temperature of the segment). The accuracy associated with this assumption can be tested by simply specifying more segments and comparing the results for different spatial discretizations. 
- The calculated temperatures are strictly only for the fractures, not for the matrix where there will be a temperature gradient. However, this assumption is not very restrictive because mass transfer is much slower than heat transfer, so the matrix temperature very near the fractures (as far as tracers will diffuse) will be essentially the same temperature as the fractures. Note that values of $k_{m} /\left(\rho C_{p}\right)_{m}$ are typically 3 to 5 orders of magnitude greater than values of $D_{m}$, meaning that heat will penetrate 1.5 to 2.5 orders of magnitude further into the matrix than tracers at any point in time.

- The temperatures for any given tracer simulation are assumed to be constant in each segment over the duration of the simulated tracer test. In reality, the temperatures in the segments will continually decrease with time, so this assumption will be most valid when tracer travel times are relatively short compared to the time scales over which temperatures change. The error introduced by this assumption will have to be evaluated for each system simulated. If tracer test durations are quite long, it would be advisable to calculate temperatures at approximately the midpoint of the tracer test rather than at the start or end of the tracer test.

The combined thermal-mass transport model was used to evaluate the ability to estimate when thermal breakthrough would occur in a multi-well EGS configuration using thermally degrading tracers. It also allowed an evaluation of the range of values of Arrhenius parameters, $A$ and $E_{a}$, that are required to obtain interpretable responses of thermally degrading tracers.

Figure 4.1 shows temperatures as a function of time in a multi-well EGS system with the following parameters:

- $250^{\circ} \mathrm{C}$ initial temperature of reservoir

- $150^{\circ} \mathrm{C}$ injection fluid temperature

- 300-hr mean fluid residence time in the reservoir (12.5 days)

- Peclet number of 10 (fluid dispersivity equal to $1 / 10$ the distance between wells)

- 0.05-cm aperture fractures

- 10-cm spacing between fractures

- Tracer matrix diffusion coefficient $=3 \times 10^{-6} \mathrm{~cm}^{2} / \mathrm{s}$

- $0.5 \%$ matrix porosity

- Rock and fluid properties corresponding to basalt and water, respectively.

These parameters correspond to a system that will exhibit thermal drawdown rather quickly, primarily because of the small fracture spacing. The different curves in Figure 4.1 correspond to different fractional distances between the injection and production wells, with a value of 1 corresponding to the temperature history at the production well. 


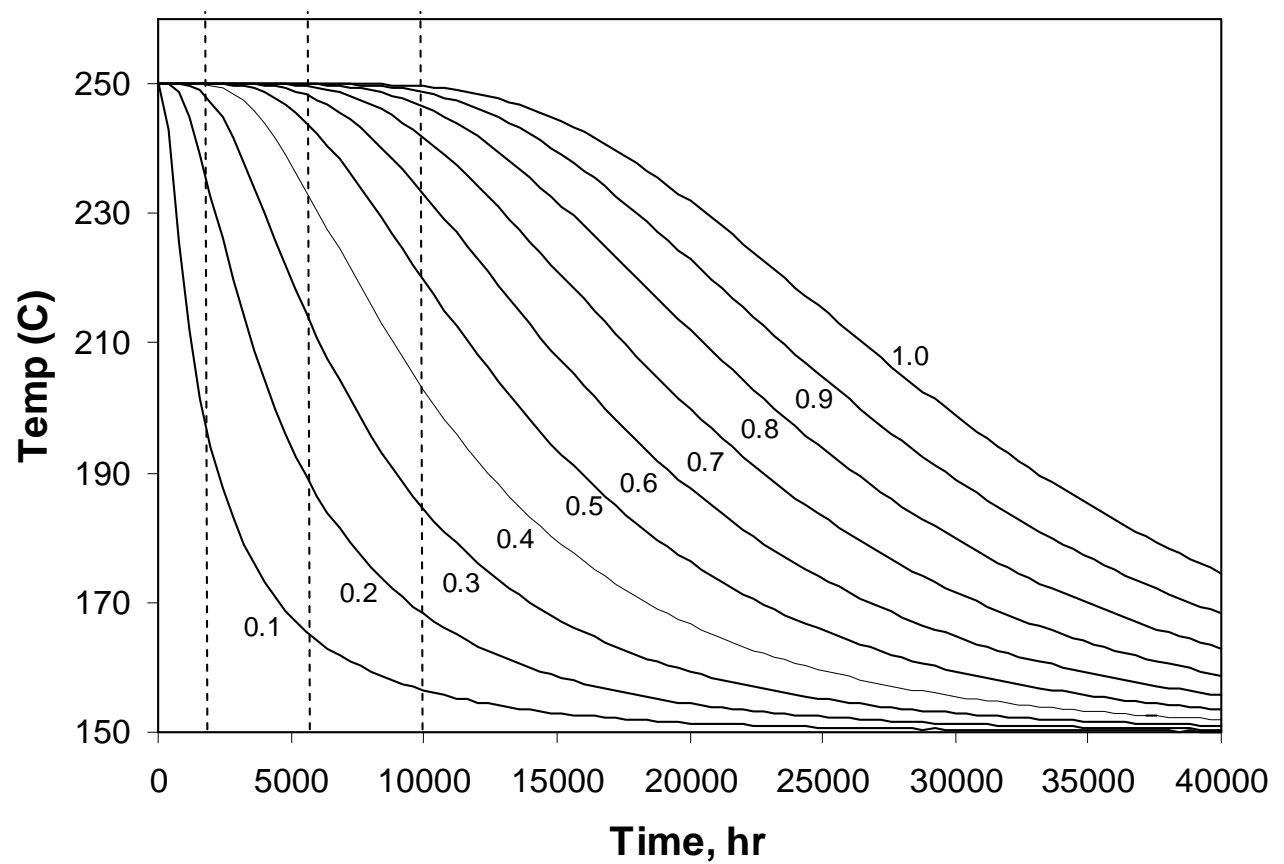

Figure 4.1. Simulated Temperature as a Function of Time and Fractional Distance Between the Injection Well and Production Well (see text for model parameters). The numbers next to the curves are the fractional distance between the wells, with 1.0 being the location of the production well. Dashed lines correspond to times when tracer tests were simulated (see Figure 4.2).

Figure 4.2 shows breakthrough curves of a conservative tracer compared to the breakthrough curves of a thermally degrading tracer at three different times after starting the injection of cool water into the reservoir. The Arrhenius decay parameters for the tracer were $E_{a}=32,000 \mathrm{cal} / \mathrm{mol}$ and $\mathrm{A}=2.5 \times 107 \mathrm{~s}^{-1}$. As Figure 4.1 shows, thermal breakthrough at the production well occurs at approximately 12,000 hours, with the drawdown rate approaching its maximum by about 15,000 hours. It is apparent that there is a significant difference in tracer breakthrough curves at 2000 and 6000 hours after the start of operations, with the peak tracer concentration increasing by $\sim 40 \%$ in the later test because of lower experienced temperatures in the flow system. The peak concentration then increases by another $\sim 33 \%$ in the test at 10,000 hours, for which temperatures have decreased even further. These results show that thermally degrading tracers can provide a good early indication of thermal breakthrough significantly before it actually occurs. There was no systematic evaluation of how much early warning might be provided by thermally degrading tracers, but the intent with future modeling is to make a quantitative link between differences in thermally decaying tracer breakthrough curves before thermal breakthrough occurs and the actual times at which thermal breakthrough occurs (with uncertainties evaluated). For instance, if the $40 \%$ increase in peak concentration between 2000 and 6000 hours could be translated into a prediction that thermal breakthrough will occur at about 12,000 hours, then multiple tracer tests with thermally degrading tracers would be shown to provide a reliable prediction of thermal breakthrough at least a factor of 2 before it actually occurs. Such information could greatly help operators in making operational EGS decisions. 


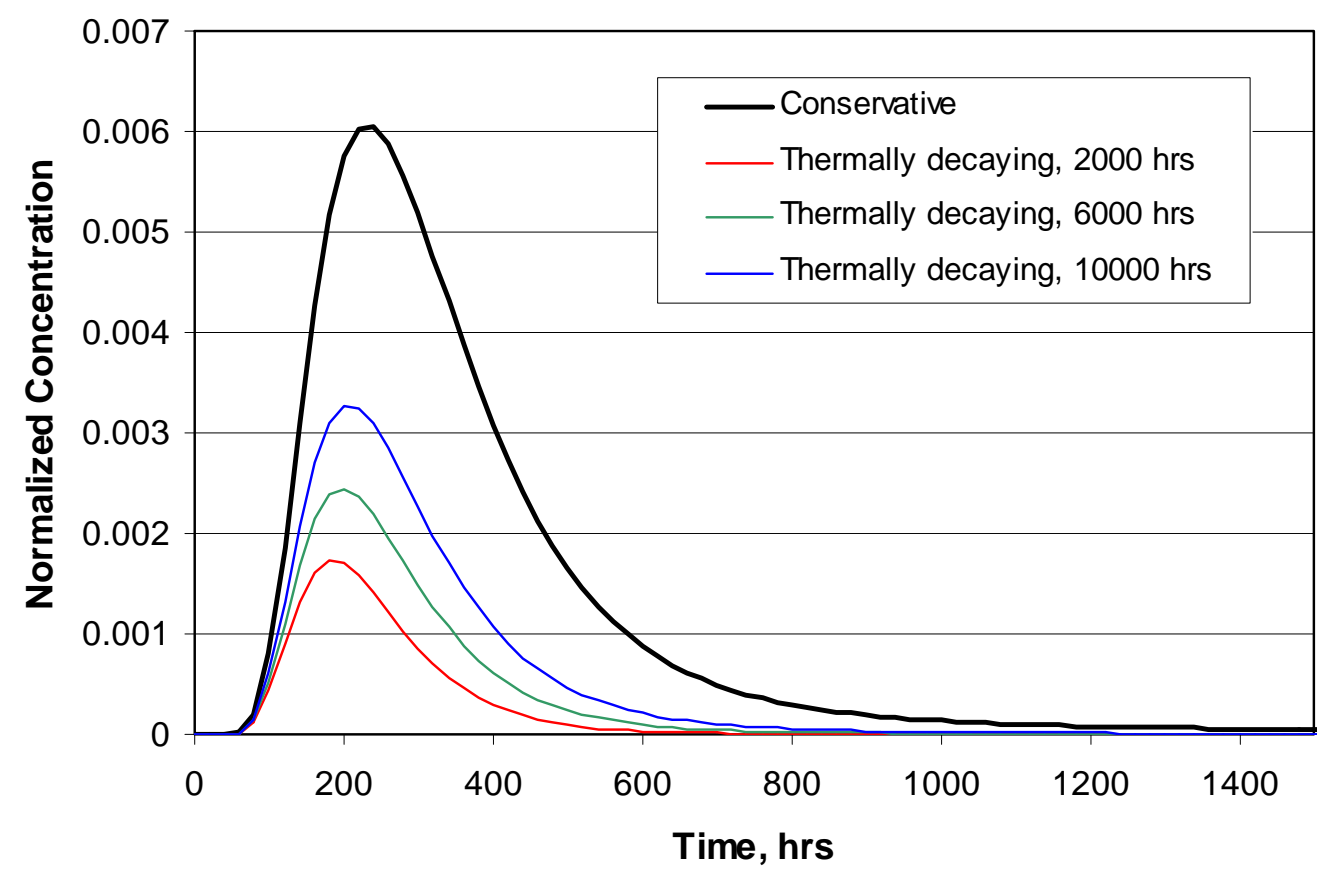

Figure 4.2. Simulated Breakthrough Curves of a Conservative Tracer and a Thermally Degrading (Thermally Decaying) Tracer at Three Different Times After the Start of Reservoir Operations. See Figure 4.1 for temperature profiles at each time.

The focus of the combined thermal and mass transport modeling for this report was on defining ranges of values of the Arrhenius decay parameters $A$ and $E_{a}$ that are necessary to obtain interpretable responses of thermally degrading tracers. If these parameter values are such that too much thermal decay occurs, then the tracers will never be detected at the production well. On the other hand, if too little decay occurs, the tracers will have the same responses as nondecaying conservative tracers. In either case, the information obtained from the tracer test will only be qualitative and cannot be used to estimate thermal breakthrough times.

Figure 4.3 shows ranges of values of $A$ and $E_{a}$ for thermally degrading tracers that provide breakthrough curves that can be quantitatively interpreted. Example breakthrough curves associated with the two dotted lines representing the upper and lower bounds are shown to the right in Figure 4.3. The ranges of $A$ and $E_{a}$ are dependent on both the ambient reservoir temperature and the mean tracer residence time in the reservoir. In fact, any tracer that exhibits thermal decay can, in principle, be used as a thermally degrading tracer; it is just a matter of whether the temperature dependence of the decay rate constant results in an appropriate amount of decay over appropriate time scales at the temperature of interest.

At the most basic level, the requirement for a readily interpretable response is that the value of the decay rate constant, $\mathrm{k}$, fall within an approximate range from $0.3 / \tau$ to $30 / \tau$, where $\tau$ is the mean tracer residence time in the system. Note that to meet this requirement, $A$ and $E_{a}$ can vary simultaneously over a two-dimensional parameter space, although as Figure 4.3 shows, this parameter space is rather narrow. These bounds on $\mathrm{k}$ can be extended more in the upward direction if a tracer has a very low detection limit and a large dynamic range of concentrations over which it can be quantified. The lower bound is fixed 
regardless of these considerations because precision rather than the detection/quantification limit is the limiting factor at low rates of degradation (i.e., the key in this case is to be able to distinguish the tracer breakthrough curve from that of a conservative tracer rather than being able to quantify the tracer at low concentrations).
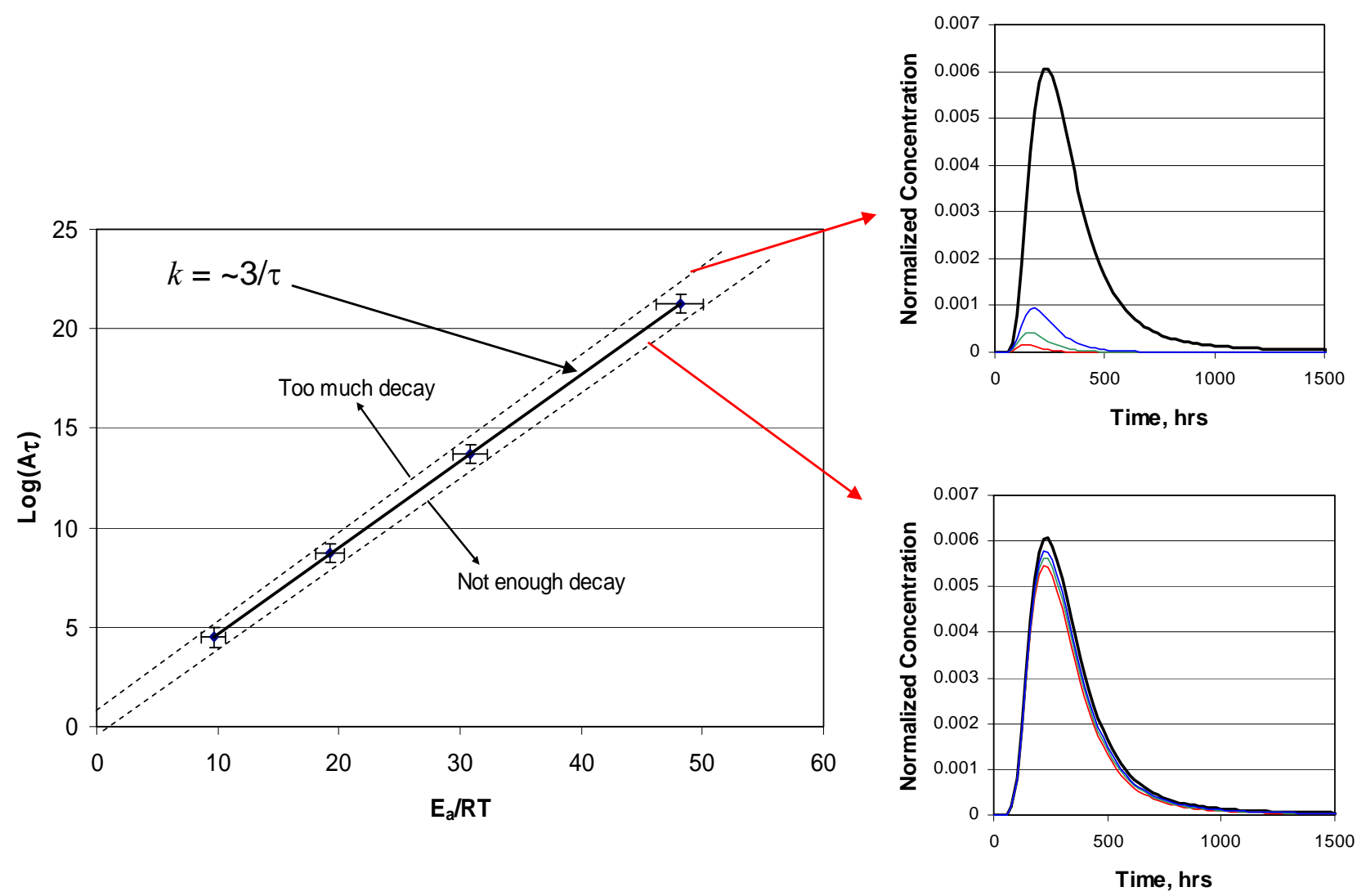

Figure 4.3. Ranges of Arrhenius Decay Parameters $A$ and $E_{a}$ (expressed as $\log (A \tau)$ and $E_{a} / \mathrm{RT}$ ) Providing Quantifiable Interpretations of Thermally Degrading Tracers Relative to Conservative Tracers. Plots to the right show breakthrough curves associated with the dashed lines in the plot on the left. The different colored breakthrough curves have the same meanings as in Figure 4.2.

\subsection{Diffusing Tracers to Estimate SA/V Ratios}

The original RELAP model (without the heat-transfer capabilities described above) was used to evaluate the potential to use conservative tracers with different diffusion coefficients to interrogate SA/V ratios in multi-well tracer tests. The general idea with this approach is that conservative tracers with smaller diffusion coefficients (i.e., larger molecules/ions) will not as readily diffuse out of fractures and into the surrounding rock matrix as tracers with larger diffusion coefficients (smaller molecules/ions), so the breakthrough curves of the former tracers will tend to have higher peak concentrations and shorter tails than the latter tracers. The differences in the peak concentrations and tailing behavior of two such tracers is dependent on the ratio of the diffusion coefficients of the tracers, the matrix porosity, and the fracture SA/V ratio in the flow system (equivalent to $1 / b$, where $b$ is the fracture half aperture). 
Specifically, the differences are dictated by the lumped parameter, $(\phi / b) \cdot \sqrt{D_{m}}$, where $D_{m}$ is different for each tracer, but $\phi$ and $b$ are fixed and dependent only on the properties of the reservoir. Values for $\phi$ and $D_{m}$ can be estimated quite readily (although uncertainties can arise in estimating the porosity of rocks with extremely low porosity), and if these parameters are properly accounted for in an interpretive model, the differences between the breakthrough curves of the two tracers can be quantitatively translated into an estimate of the $\mathrm{SA} / \mathrm{V}$ ratio $(1 / b)$.

Figure 4.4 shows an example of the differences in simulated breakthrough curves as a function of fracture SA/V ratio for bromide and a naphthalene sulfonate, two conservative and non-degrading tracers that should have a diffusion coefficient contrast of about a factor of 3.3 based on molecular size considerations (with bromide having the larger diffusion coefficient). The parameters used to generate the curves of Figure 4.4 are the same as those listed above (Section 4.1) for the thermally degrading tracer simulations. The matrix diffusion coefficient for bromide was assumed to be $1 \times 10^{-5} \mathrm{~cm}^{2} / \mathrm{s}$, and the matrix diffusion coefficient for the naphthalene sulfonate was assumed to be $3 \times 10^{-6} \mathrm{~cm}^{2} / \mathrm{s}$. As seen in Figure 4.4, the tracer breakthrough curves have significant differences for both assumed values of SA/V ratio, and the differences decrease as the $\mathrm{SA} / \mathrm{V}$ ratio decreases. These differences can, in principle, be used to obtain estimates of SA/V ratios in EGS reservoirs. Given that conservative tracers can provide estimates of reservoir swept volume, the $\mathrm{SA} / \mathrm{V}$ ratios estimated from diffusing tracers can be used to estimate total surface area in a reservoir. Future efforts will focus on exploring the uncertainties associated with this method of estimating surface area, particularly with respect to the effects of system heterogeneity (in both fracture apertures and matrix porosities) on surface-area estimates. 


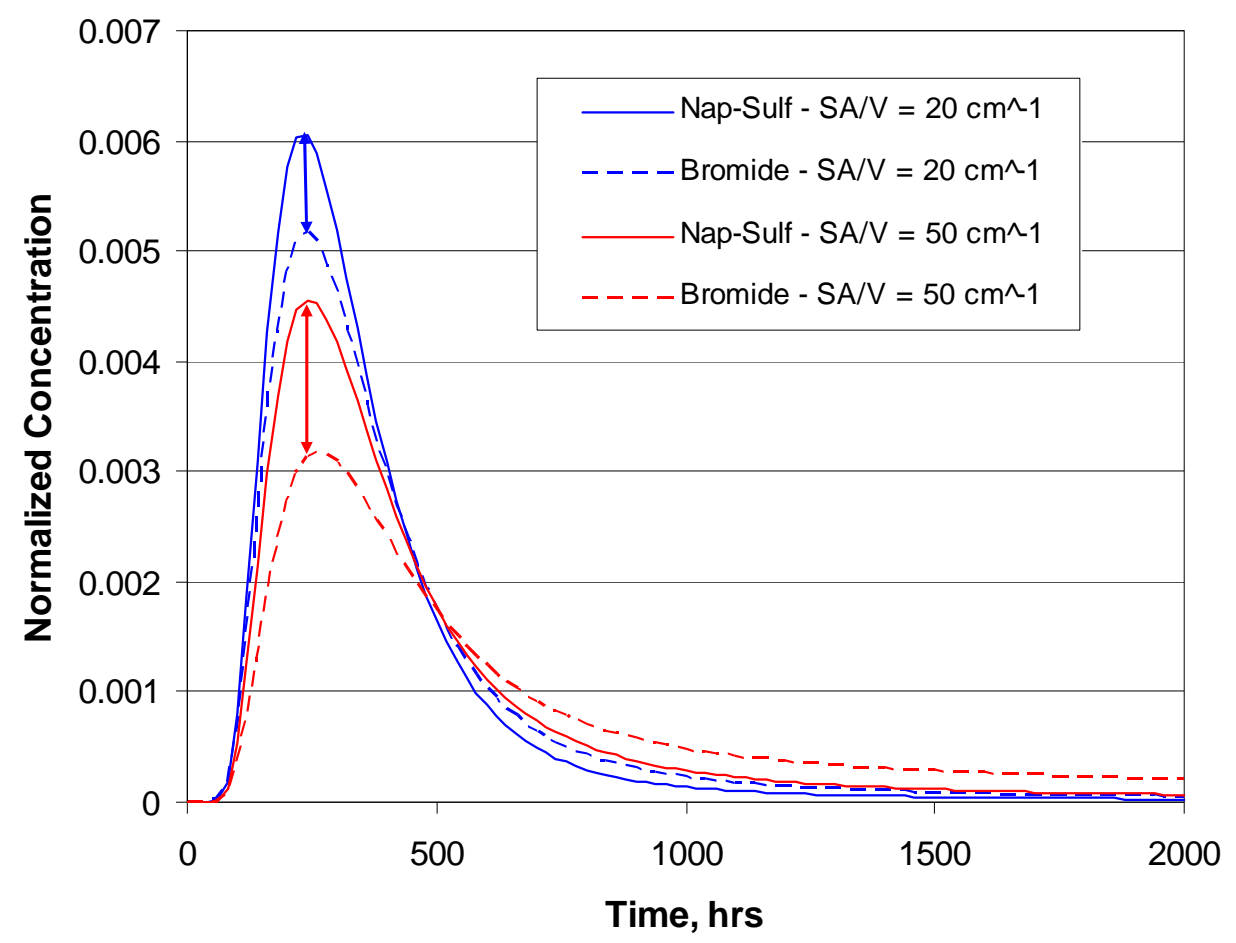

Figure 4.4. Simulated Differences Between Bromide and a Naphthalene Sulfonate Tracer as a Function of SA/V in an EGS Reservoir. Arrows show that differences in peak concentrations increase as $\mathrm{SA} / \mathrm{V}$ increases. The bromide is assumed to have a diffusion coefficient that is 3.3 times larger than that of the naphthalene sulfonate. See Section 4.1 for model parameters used in simulations. 


\subsection{Multicomponent Numerical Model Simulations of the Use of Cation-Exchanging Tracers for Surface Area Estimation}

The Multicomponent Transport (MULTRAN) computer model (Sullivan et al. 2003) was used to conduct exploratory simulations to determine the potential for using cation-exchanging tracers to interrogate surface area in both multi-well and single-well tracer tests in EGS reservoirs. MULTRAN is currently an isothermal model that essentially solves Equations (4.1) and (4.2) without the restrictions imposed by the Laplace transform solution of RELAP (most notably no interacting species and steadystate flow conditions). Without these restrictions, MULTRAN can simulate the flow interruptions and flow reversals associated with single-well tracer tests. MULTRAN simulates the transport of cationexchanging tracers by solving mass-action equations for cation exchange equilibria simultaneously with the transport equations. For the simulations conducted for this report, a simple three-component system was simulated involving a monovalent cation tracer that exchanges with both a monovalent and a divalent cation present in the ambient reservoir. The relevant reactions are:

$$
\begin{aligned}
& \mathrm{A}+\mathrm{BX} \Rightarrow \mathrm{AX}+\mathrm{B} \\
& 2 \mathrm{~A}+\mathrm{CX}_{2} \Rightarrow 2 \mathrm{AX}+\mathrm{C} \\
& 2 \mathrm{~B}+\mathrm{CX}_{2} \Rightarrow 2 \mathrm{BX}+\mathrm{C}
\end{aligned}
$$

where $\mathrm{A}$ and $\mathrm{B}=$ monovalent cations $\left(\mathrm{Rb}^{+}\right.$and $\mathrm{Na}^{+}$for this study $), \mathrm{C}=$ divalent cation $\left(\mathrm{Ca}^{2+}\right.$ for this study), and $\mathrm{X}=$ a monovalent negatively charged surface site. The relevant mass action equations are:

$$
\begin{gathered}
\mathrm{Q}_{1}=\frac{[\mathrm{AX}][\mathrm{B}]}{[\mathrm{A}][\mathrm{BX}]} \\
\mathrm{Q}_{2}=\frac{[\mathrm{AX}]^{2}[\mathrm{C}]}{[\mathrm{A}]^{2}\left[\mathrm{CX}{ }_{2}\right]} \\
\frac{\mathrm{Q}_{2}}{\mathrm{Q}_{1}^{2}}=\frac{[\mathrm{BX}]^{2}[\mathrm{C}]}{[\mathrm{B}]^{2}\left[\mathrm{CX}_{2}\right]} \\
\mathrm{CEC}=\frac{\phi}{\rho_{B}}\left([\mathrm{AX}]+[\mathrm{BX}]+2\left[\mathrm{CX}_{2}\right]\right) \quad \text { (surface cation balance) }
\end{gathered}
$$

where $\quad[\mathrm{i}]=$ concentration of species $\mathrm{i}$, moles $/ \mathrm{L}$ of solution

$\mathrm{Q}_{\mathrm{i}}=$ ion exchange constant

$\mathrm{CEC}=$ cation exchange capacity measured with lithium ion, eq $/ \mathrm{kg}$

$\rho_{B}=$ bulk density of rock, $\mathrm{kg} / \mathrm{L}$ of bulk rock.

Note that the $Q_{i}$ values used here should not be confused with equilibrium constants because they are defined in terms of species concentrations, not activities.

Figure 5.1 provides an example of the dependence of the breakthrough curve of a cation-exchanging tracer on the fracture $\mathrm{SA} / \mathrm{V}$ ratio in a cross-hole tracer test using the same model parameters as in 
Section 4.1 for the thermally degrading tracer simulations (except in this case, the system is assumed isothermal). The breakthrough curves of a conservative tracer are also shown in Figure 5.1; estimates of the SA/V ratio from cation-exchanging tracers will ultimately be based on differences between conservative and cation-exchanging tracer breakthrough curves. Note that the differences between the conservative tracer breakthrough curves in Figure 5.1 provide a good approximation to the differences that could be expected in the breakthrough curves of two tracers with diffusion coefficients that differ by a factor of 4 in a system with a single value of SA/V ratio.

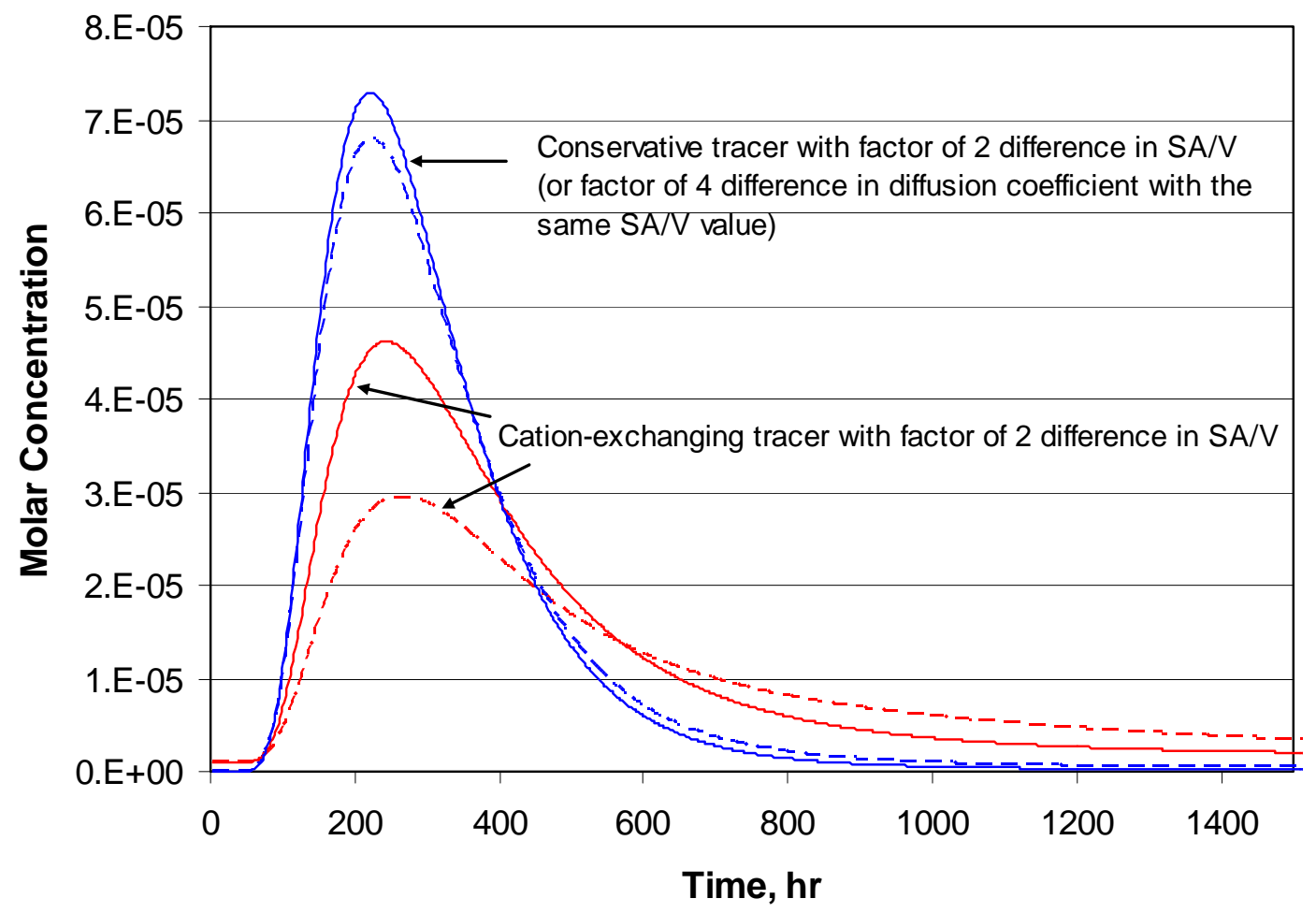

Figure 5.1. Simulated Differences in Conservative and Cation-Exchanging Tracer Breakthrough Curves for SA/V Values of $10 \mathrm{~cm}^{-1}$ and $20 \mathrm{~cm}^{-1}$. Cation-exchange parameters correspond approximately to those of $\mathrm{Rb}^{+}$in a system dominated by $\mathrm{Na}^{+}$and $\mathrm{Ca}^{2+}$ (as resident cations). Note that the difference in conservative tracer breakthrough curves at the two different SA/V values roughly corresponds to the differences that could be expected for conservative tracers with a factor of 4 difference in diffusion coefficients at either SA/V value.

Cation-exchanging tracers offer at least two advantages over diffusing tracers in estimating SA/V ratios in multi-well tracer tests: 1) they do not rely on matrix diffusion (i.e., they can provide estimates of surface area in systems with extremely low matrix porosities that may not exhibit a breakthrough curve dependence on diffusion coefficients) and 2) they can provide more sensitive estimates of surface area than conservative tracers with different diffusion coefficients in systems where there is significant matrix diffusion. This is because they behave as if they are conservative tracers with very large diffusion coefficients in such systems. The latter advantage is apparent in Figure 5.1. Depending on the cation exchange capacity (CEC) in an EGS system, different cations with different exchange constants (Q values) can be selected to interrogate the surface area. For instance, lithium ion $\left(\mathrm{Li}^{+}\right)$could serve as a weakly exchanging cation tracer in systems with high values of CEC, and cations such as $\mathrm{Cs}^{+}$and $\mathrm{Rb}^{+}$ could serve as strongly exchanging cation tracers in systems with low CEC values. The only restriction is 
that the cation tracer must have a relatively low background concentration in the reservoir so that its breakthrough curve can be readily distinguished from the background. The cations $\mathrm{Li}^{+}, \mathrm{Cs}^{+}$, and $\mathrm{Rb}^{+}$all tend to have low background concentrations in most rock-water systems.

Figure 5.2 shows an example of the dependence of the breakthrough curve of a cation-exchanging tracer on fracture SA/V ratio in a single-well tracer test. Single-well tests have not historically been used in geothermal applications, but they offer a significant potential advantage over multi-well tests in that they could be used to interrogate or develop preliminary estimates of the parameters based on single-well test results before a second well is drilled. The simulations for Figure 5.2 assumed 10 hours of water/tracer injection, followed by 2 hours of chase water injection, followed by 20 hours of "shut-in," and finally, withdrawal of water/tracers starting at 32 hours. Cation exchange coefficients typical of $\mathrm{Rb}^{+}$, $\mathrm{Na}^{+}$, and $\mathrm{Ca}^{2+}$ (Appelo 1996) were used to generate the breakthrough curves, with the assumption that $\mathrm{Rb}^{+}$was the tracer, and $\mathrm{Na}^{+}$and $\mathrm{Ca}^{2+}$ were the two primary resident cations in the reservoir (dominant mono- and di-valent cations, respectively). Figure 5.1 illustrates several key points:

- The breakthrough curve of the $\mathrm{Rb}^{+}$is quite sensitive to a difference of a factor of 2 in the $\mathrm{SA} / \mathrm{V}$ ratio in the system. It is apparent that the $\mathrm{Rb}^{+}$breakthrough curve could readily distinguish between these two SA/V ratios in this hypothetical system.

- The $\mathrm{Rb}^{+}$breakthrough curve is surprisingly insensitive to the CEC of the system, with a factor of 10 difference in CEC, resulting in only a minor change in the breakthrough curve. This result is very encouraging because it suggests that $\mathrm{SA} / \mathrm{V}$ ratio estimates will not be highly sensitive CEC values, which can be difficult to estimate in fractured rock flow systems.

- Conservative tracers with different diffusion coefficients could not be used effectively in this hypothetical system to interrogate surface area because the differences in their breakthrough curves (approximated by the differences in the conservative tracer breakthrough curves at the two different $\mathrm{SA} / \mathrm{V}$ ratios) are too small to be distinguished (especially when considering typical analytical measurement errors).

The simulation results shown in Figure 5.1 and Figure 5.2 represent only preliminary scoping exercises. Systematic evaluations of sensitivities and uncertainties associated with the use of cationexchanging tracers to interrogate SA/V ratios in EGS systems are planned as future activities. 


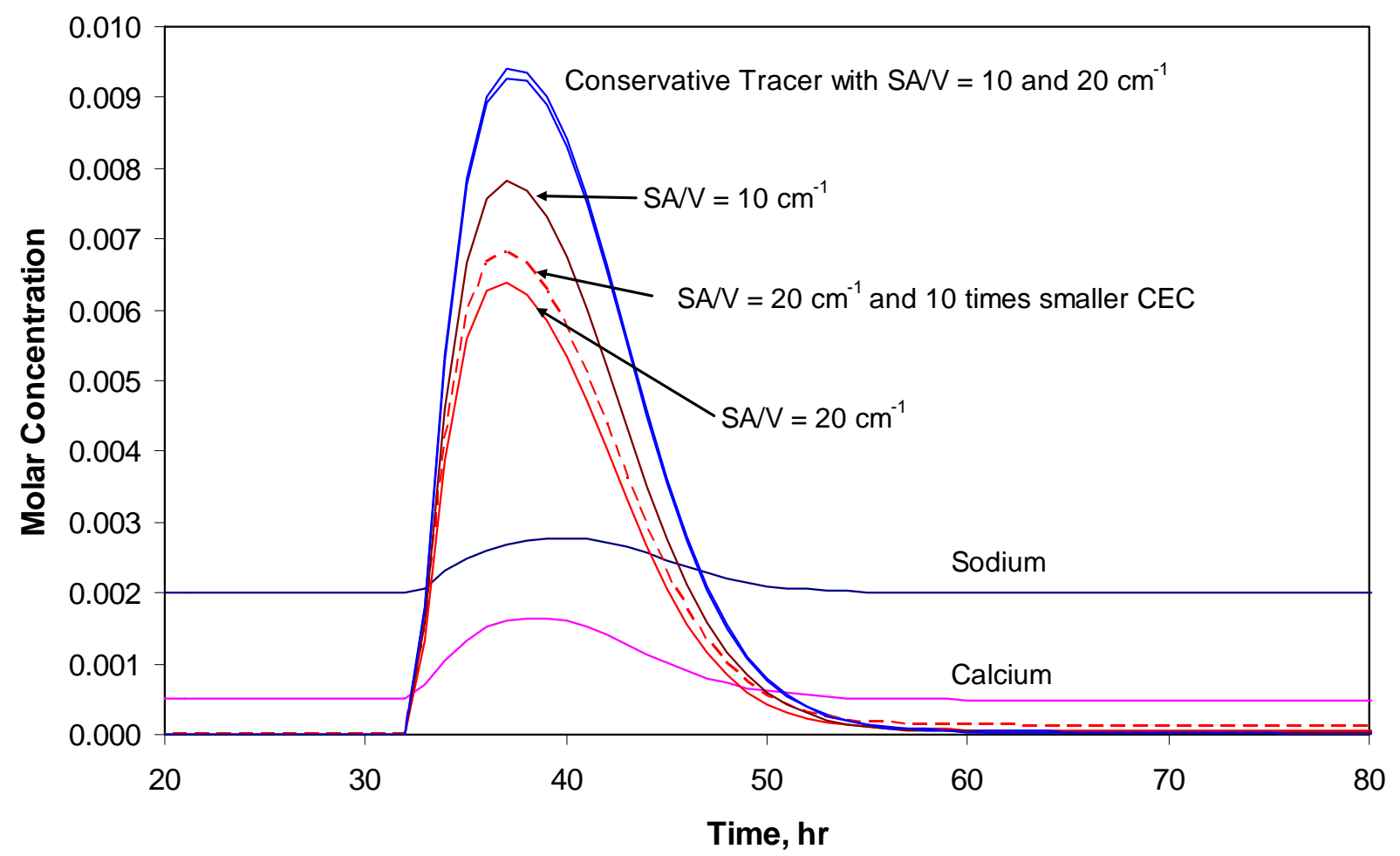

Figure 5.2. Simulated Differences in $\mathrm{Rb}^{+}$Breakthrough Curves (brown and red) as a Function of SA/V and CEC in a Single-Well Tracer Test (see text for test assumptions). The sodium and calcium "breakthrough curves" are a result of $\mathrm{Na}^{+}$and $\mathrm{Ca}^{2+}$ being displaced by $\mathrm{Rb}^{+}$at cation exchange sites. Note that the difference in conservative tracer breakthrough curves at the two different $\mathrm{SA} / \mathrm{V}$ values roughly corresponds to the differences that could be expected for conservative tracers with a factor of 4 difference in diffusion coefficients at either SA/V value. 


\subsection{Path Forward}

This document describes the requirements and the initial development of numerical and semianalytical models to be used for screening, designing, and evaluating single-well and multi-well tracer tests used in characterizing EGS reservoirs. Numerical model development will continue for simulating different discrete fracture spacing for the STOMP two-dimensional, radially symmetric model used for single-well, injection-withdrawal tests. Three-dimensional STOMP simulations will also be constructed for more complex hydrostratigraphy and for simulating multi-well tests. Current limitations in the STOMP code regarding dual-continuum and well features in the energy mode will also be addressed. Further work is also planned for evaluating the suitability of the TOUGHREACT code for simulating these tracer tests, particularly the dual-continuum MINC features of the code.

The scoping calculations conducted using the RELAP and MULTRAN models will be expanded to 1) identify optimal properties of thermally degrading, diffusing, and cation-exchanging tracers as a function of reservoir characteristics and 2) quantify uncertainties associated with tracer test estimates of $\mathrm{SA} / \mathrm{V}$ ratios as a function of reservoir parameters and heterogeneities in these parameters. Under (2), the following specific activities are planned:

- Use RELAP to evaluate the effects of heterogeneity in both fracture apertures and matrix porosity on the breakthrough curves of conservative tracers with different diffusion coefficients. Also, incorporate into the heat and mass transport version of RELAP the capability to simulate the effects of changes in tracer diffusion coefficients as a function of temperature. This work will help quantify the uncertainties associated with estimating surface area from conservative tracers with different diffusion coefficients.

- Use the heat and mass transport version of RELAP to determine how far in advance thermal breakthrough can be reliably predicted in multi-well tracer tests with thermally degrading tracers. This evaluation will be done over a range of assumed reservoir parameters, including heterogeneity, in fracture apertures and fracture spacings.

- Further evaluate the sensitivity of cation-exchanging tracer breakthrough curves to cation exchange capacity and SA/V ratios, as well as reservoir heterogeneity in these parameters. Also, use MULTRAN to evaluate the influence of changes in cation exchange constants with temperature on tracer transport behavior (by adding a coupled heat-transport capability to MULTRAN and allowing cation exchange constants to vary with temperature). This work will help quantify the uncertainties associated with estimating SA/V ratios from cation-exchanging tracers. In addition to these activities, more targeted simulations and capabilities will be developed based on results of laboratory testing of tracers at high temperature and pressure with sediments from potential sites currently underway at LANL and BNL. Site characterization from potential field testing sites will be used to develop sitespecific simulations for design analysis of planned field tracer tests. These site-specific models will also be used to interpret field tracer test results.

In addition to these activities, more targeted simulations and capabilities will be developed based on the results of laboratory testing of tracers at high temperature and pressure with sediments from potential sites currently underway at LANL and BNL. Site characterization from potential field testing sites will be used to develop site-specific simulations for design analysis of planned field tracer tests. These sitespecific models will also be used to interpret field tracer test results. 



\subsection{References}

Adams MC and J Davis. 1991. "Kinetics of Fluorescein Decay and its Application as a Geothermal Tracer." Geothermics 20:53-66.

Appelo CAJ. 1996. "Multicomponent ion exchange and chromatography in natural systems." In: Reactive Transport in Porous Media. PC Lichtner, CI Steefel, and EH Oelkers (Editors). Reviews in Mineralology 34:193-227.

Bruseau ML, KM Bronson, S Ross, NT Nelson, and TD Carlson. 2003. “Application of Gas-Phase Partitioning Tracer Test to Characterize Immiscible-Liquid Contamination in the Vadose Zone Beneath a Fuel Depot." Vadose Zone Journal 2:148-153.

Chemburkar RM, LF Brown, BJ Travis, and BA Robinson. 1991. "Numerical Determination of Temperature Profiles in Flowing Systems from Conversions of Chemically Reacting Tracers." Chemical Engineering Science 46(5):1349-1360.

DOE_-U.S. Department of Energy. 1980. Proceedings of Special Panel on Geothermal Model Intercomparison Study. DOE/SF/11459-1, Stanford University, Stanford, California.

Fayer S, P Rose, S Petty, MD Deo, and T Xu. 2009. "A Computational Technique for Estimating the Fracture Surface Area Adjacent to a Newly Stimulated Well within an Engineered Geothermal System." In: Proceedings of TOUGH Symposium 2009, Lawrence Berkeley National Laboratory, Berkeley, California, September 14-16, 2009.

Maloszewski P and A Zuber. 1984. "Interpretation of artificial and environmental tracers in fissured rocks with a porous matrix.” In: Isotope Hydrology, pp. 635-651, International Atomic Energy Agency (IAEA), Vienna, Austria.

Maloszewski P and A Zuber. 1985. "On the theory of tracer experiments in fissured rocks with a porous matrix." Journal of Hydrology 79:333-358.

MIT-Massachusetts Institute of Technology. 2006. The Future of Geothermal Energy, Impact of Enhanced Geothermal Systems (EGS) on the United States in the 21st Century. Cambridge, Massachusetts.

Nicol DAC and BA Robinson. 1990. "Modelling the Heat Extraction from the Rosemanowes HDR Reservoir." Geothermics 19(3):247-257.

O'Sullivan MJ, K Pruess, and MJ Lippman. 2001. "State of the art of geothermal reservoir simulation." Geothermics 30:395-429.

Pruess K. 1983. GMINC-A Mesh Generator for Flow Simulations in Fractured Reservoirs. LBL-15227, Lawrence Berkeley Laboratory, Berkeley, California.

Pruess K and TN Narasimhan. 1982. A Practical Method Fluid and Heat Flow in Fractured Porous Media. LBL-13487, Lawrence Berkeley Laboratory, Berkeley, California.

Pruess K. 1992. Brief Guide to the MINC-Method for Modeling Flow and Transport in Fractured Media. LBL-32195, Lawrence Berkeley Laboratory, Berkeley, California. 
Pruess K, C Oldenburg, and G Moridis. 1999. TOUGH2 user's guide. Version 2.0. LBL-43134, Lawrence Berkeley Laboratory, Berkeley, California.

Reimus PW, G Pohll, T Mihevc, J Chapman, L Papelis, B Lyles, S Kosinski, R Niswonger, and P Sanders. 2003. "Testing and Parameterizing a Conceptual Model for Radionuclide Transport in a Fractured Granite using Multiple Tracers in a Forced-Gradient Test." Water Resources Research, 39(12):1350, doi:10.1029/2002WR001597.

Reimus PW and TJ Callahan. 2007. "Matrix Diffusion Rates in Fractured Volcanic Rocks at the Nevada Test Site: Evidence for a Dominant Influence of Effective Fracture Apertures." Water Resources Research 43, W07421, doi:10.1029/2006WR005746.

Robinson BA, JW Tester, and LF Brown. 1988. "Reservoir Sizing Using Inert and Chemically Reacting Tracers." SPE Formation Evaluation 3:227-234.

Rose PE and MC Adams. 1994. "The Application of Rhodamine WT as a Geothermal Tracer." Geothermal Resources Council Transactions 18:237-240.

Sennum GI, RN Dietz, TW D’Otavvio, RW Goodrich, EA Cote, and DJ Spandau. 1989. A Perfluorocarbon Tracer Transport and Dispersion Experiment in the North Sea Ekofisk Oil Field. BNL-43811, Brookhaven National Laboratory, Upton, New York.

Sullivan EJ, PW Reimus, and DA Counce. 2003. "Transport of a Reactive Tracer in Saturated Alluvium Described using a Three-Component Cation-Exchange Model," Journal of Contaminant Hydrology 62-63:675-694.

Tang JS. 1995. "Partitioning Tracers and In-Situ Fluid Saturation Measurements." SPE Formation Evaluation. Society of Petroleum Engineers, March 1995.

Warren JE and PJ Root. 1963. "The Behavior of Naturally Fractured Reservoirs." Society of Petroleum Engineers Journal. Transactions, AIME, 228:245-255.

Watson TB, R Wilke, RN Dietz, J Heiser, and P Kalb. 2007. "The Atmospheric Background of Perfluorocarbon Compounds Used as Tracers.” Environmental Science and Technology 41:6909-6913.

White MD and M Oostrom. 2000. STOMP Subsurface Transport Over Multiple Phase: Theory Guide. PNNL-11216 (UC-2010), Pacific Northwest National Laboratory, Richland, Washington.

White MD and M Oostrom. 2006. STOMP Subsurface Transport Over Multiple Phase: User's Guide. PNNL-15782 (UC-2010), Pacific Northwest National Laboratory, Richland, Washington.

Xu T, E Sonnenthal, N Spycher, and K Pruess. 2006. TOUGHREACT V1.2 User's Guide: A Simulation Program for Nonisothermal Multiphase Reactive Geochemical Transport in Variably Saturated Geologic Media. LBNL-55460, Lawrence Berkeley Laboratory, Berkeley, California. 



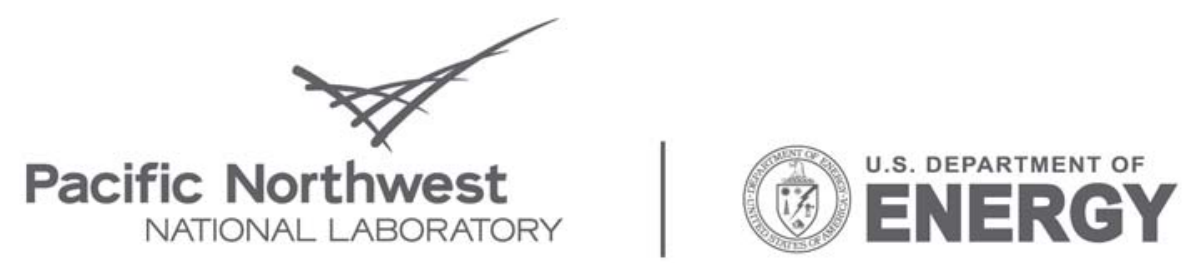

Proudly Operated by Battelle Since 1965

902 Battelle Boulevard

P.O. Box 999

Richland, WA 99352

1-888-375-PNNL (7665)

www.pnl.gov 